\title{
The effect of sleeper interventions on railway track performance
}

\author{
Taufan Abadi $^{1}$, Louis Le Pen ${ }^{2}$, Antonis Zervos ${ }^{3}$, William Powrie ${ }^{4}$,
}

\begin{abstract}
The sleeper / ballast interface is an essential stage in the transfer of train loads from a railway track structure into the ground. Generally, only a small number of ballast grains support the sleeper base. The resulting localised contact stresses can be very high, especially for modern concrete sleepers on hard igneous ballast. This may result in damage to both sleepers and ballast, and reduce the stability of the interface. The paper presents results from cyclic loading tests carried out to explore the potential for performance improvement through the adoption of different sleeper types and modifications to the sleeper / ballast interface. Measurements of resilient performance, plastic settlement, sleeper / ballast contact number and area, shoulder movement, ballast breakage and attrition and the development of ballast longitudinal pressure are used to explore and explain the effect of each intervention. It is shown that twin-block sleeper types and under sleeper pads (USP) have the potential to reduce maintenance requirements and whole life costs.
\end{abstract}

Keywords: Settlement, stiffness, repeated loading, ballast, railways, railroad, sleeper, bearer, tie

The article was accepted for publication in ASCEs Journal of Geotechnical and Geoenvironmental Engineering on 5 September 2018. This is the authors accepted version of the manuscript which has been made available from the University of Southampton's online repository. A data set is also available.

\footnotetext{
${ }^{1}$ Research Fellow, Infrastructure Research Group, School of Engineering, University of Southampton, Southampton, SO17 1BJ, United Kingdom

${ }^{2}$ Senior Research Fellow, Infrastructure Research Group, School of Engineering, University of Southampton, Southampton, SO17 1BJ, United Kingdom. Corresponding author louis.lepen@soton.ac.uk

${ }^{3}$ Associate Professor in Geomechanics, Deputy Head of the Infrastructure Research Group, School of Engineering, University of Southampton, Southampton, SO17 1BJ, United Kingdom

${ }^{4}$ Professor of Geotechnical Engineering, School of Engineering, University of Southampton, Southampton, SO17 1BJ, United Kingdom
} 


\section{Introduction}

Most of the world's railways run on ballasted track, with rails supported by sleepers placed on a ballast bed. Trafficking results in a gradual loss of alignment and level; tamping is then employed to adjust the track geometry back to its intended design profile. Recent increases in rail traffic and intensity of use (Department for Transport, 2013; Powrie, 2014) have reduced the time available for maintenance. Thus there are considerable benefits in reducing the maintenance requirements of ballasted track, in terms of both costs and infrastructure availability.

A key factor contributing to track geometry deterioration is ballast settlement, which can be influenced significantly by conditions at the sleeper / ballast interface. Recent practice has generally been to use hard, steel-reinforced concrete sleepers on hard granite ballast. This results in a relatively few, highly stressed, points of contact at the sleeper / ballast interface, which has been identified as a cause of ballast damage and deterioration (Raymond, 1987). This paper explores, by means of laboratory tests over millions of load cycles, the potential to reduce ballast permanent settlement through the use of different sleeper types / shapes and modification of the ballast / sleeper interface. Insights into the micromechanical mechanisms of behaviour are obtained through the measurement of sleeper / ballast grain contact number and area, grain breakage and attrition, the development of longitudinal stresses within the ballast bed, and vertical and lateral movements.

\section{Background}

Sleepers keep the rails at the correct gauge and distribute the loads into the ballast underneath. Sleepers were probably first introduced in large numbers on the Liverpool and Manchester Railway in 1837, when they replaced the unconnected stone supports used in the original construction seven years earlier (Morgan, 1971).

Various sleeper materials and shapes are in use. Rectangular section timber sleepers were predominant from an early stage of railway track development until relatively recently. Over the past few decades, timber has generally given way to reinforced concrete for improved durability and to accommodate increasing axle loads and train speeds. However, timber sleepers continue to be used in certain conditions, for example in switches and crossings $(S \& C)$ and to mitigate stiff track support conditions such as on ballasted overbridges.

Concrete sleepers are generally pre-cast concrete beams, reinforced internally with pre-stressed steel (BSI, 2009a; Taylor, 1993). Concrete sleepers have a longer service life and a superior load carrying capacity to their timber predecessors, and their greater weight contributes to track stability. However, an advantage of timber sleepers is that they spread ballast contact forces over a larger contact area through ballast grain indentation, which concrete sleepers do not allow. Thus the adoption of concrete sleepers has perhaps inadvertently resulted in higher contact stresses and fewer contact points between the ballast and the sleeper.

Steel sleepers (BSI, 2000) are generally viewed as sturdier than timber and less expensive than prestressed concrete sleepers. However, they have not seen widespread adoption even on secondary routes, mainly because installation can be problematic. In particular, it is difficult to create homogeneous and complete contact with the ballast within the $\cap$-shaped profile of a steel sleeper. Perhaps as a result, steel sleepers may settle more than timber (Manalo et al., 2010); although where they can be installed effectively, laboratory tests and modelling have indicated potential advantages (Laryea et al., 2014). They may also be susceptible to corrosion, particularly at the railseats where there is a risk of fatigue. For these reasons, steel sleepers have generally only been used as a last resort on very fouled ballast, where they can easily be installed by pushing them into the softer support. 
Plastic or composite sleepers are a relatively recent development. Combinations of raw materials (e.g. plastic, rubber and waste fibreglass) are used to create a sleeper with (ideally) the compliance of timber and the durability of concrete. Manufacture using recycled materials gives further sustainability benefits. They have not (yet) seen widespread adoption, although in some parts of the world composite bearers have been used in specialized applications such as S\&C.

Sleepers are generally made as single (mono-) blocks, except for concrete sleepers, which may also be in the form of a twin block. A twin-block sleeper comprises two concrete blocks, one beneath each rail, tied together by a steel rod. In terms of cost and performance, it is unclear which is better and there are strongly-held but conflicting views. Twin-block concrete sleepers have been employed in France for both high speed and slower lines. In the UK, concrete sleepers are traditionally monoblock although HS1 has twin-block sleepers.

Under-sleeper pads (USPs) for the improvement of mechanical performance (as opposed to noise reduction) have been used on some European new-build high speed railways in recent years (Johansson et al., 2006; Witt, 2008; Schneider et al., 2011), and small scale laboratory testing and modelling has shown potential advantages (e.g. Safari Baghsorkhi et al., 2015). USPs are attached to the sleeper soffit to provide a more compliant interface with the ballast. In addition to having suitable damping properties and stiffness, USPs must be able to resist abrasive wear by the ballast and to withstand many millions of loading cycles from passing trains without losing their elasticity. USPs are available in various thicknesses and may comprise either a single or multiple layers, e.g. with an outer material protecting the inner layer from abrasive wear.

USPs may be used primarily to reduce damage to the ballast by increasing the contact area and reducing contact stresses (Johansson et al., 2006; Witt, 2008; Lakusic et al., 2010; Abadi et al., 2015), or to smooth or reduce the variations in track stiffness typical of transition zones (Insa et al., 2013). USPs have also been shown to modify elastic deflection and permanent settlements (Auer et al., 2013), and are generally considered to improve the track quality (reducing rates of track geometry deterioration, ballast and sleeper wear, and rail corrugation; UIC, 2008, 2009).

While the relative advantages and disadvantages of different sleeper materials may be stated qualitatively, quantitative data from independently reviewed and publicly available sources are scarce. Similarly, the micromechanical mechanisms by which USPs improve the performance of reinforced concrete sleepers are not fully quantitatively understood.

Abadi et al. (2018) investigated the influence of ballast type and arrangement on track performance. This paper describes further tests carried out using the same general apparatus, the Southampton Railway Testing Facility (SRTF), to investigate the effect of sleeper shape / material and USPs on resilient (in-cycle) and plastic (cumulative) sleeper settlements. Common testing protocols were followed to ensure comparability of data both within the current test series and with the earlier work. In each test, at least 3 million loading cycles of a 20 tonne equivalent (20 TE) axle load were applied. To gain insights into the mechanisms controlling the development of permanent and resilient settlements, measurements of sleeper-ballast contact area and number, ballast shoulder (lateral) movements, grain breakage and abrasion, and longitudinal stress within the ballast bed were also made.

\section{Methods and materials}

\subsection{Methods}

The basic test philosophy and method were as described in Abadi (2015) and Abadi et al., (2018). For convenience, they are summarized here, before the specific adaptations for the sleeper intervention 
tests are described.

\section{Test preparation}

The SRTF represents a single sleeper bay of track. The apparatus comprises two vertical sides each $5.0 \mathrm{~m}$ long and $0.65 \mathrm{~m}$ high, constructed from heavy steel sections and panels, fixed to a strong floor at a typical sleeper spacing of $0.65 \mathrm{~m}$. Conditions are maintained as near as practicable to plane strain, as would be expected to occur below most of a train (i.e., except at the ends) in reality. $25 \mathrm{~mm}$ thick wooden panels are attached to the inside walls of the apparatus, with a double layer of plastic sheeting to minimise boundary friction.

Rubber mats placed at the bottom of the ballast bed represent a slightly compressible subgrade and provide friction on the base. A fuller description is given by Le Pen \& Powrie (2011). In the current tests, a loading beam was used to transfer load from a single vertical hydraulic actuator onto short sections of 60EI/UIC60 rail (BSI, 2011). The general test arrangement is shown in Figure 1.

The experimental procedure followed for all the tests reported in this paper was as follows:

1. The ballast was placed to the full width and $300 \mathrm{~mm}$ depth (up to the level of the sleeper soffit) and compacted with a total of 22 passes of a $400 \mathrm{~mm} \times 320 \mathrm{~mm}, 26 \mathrm{~kg}$ plate vibrator giving a 5 $\mathrm{kN}$ compaction force, and the surface levelled at the same time.

2. The sleeper was placed on top of the ballast. The crib ballast was constructed and the shoulder ballast raised to the level of the upper sleeper surface (Figure 2).

3. Linear variable differential transformers (LVDT) for the measurement of deflections were installed in appropriate locations depending on sleeper type (Figure 2 shows the arrangement for a mono-block).

4. The loading beam was placed across the railheads and aligned with the connection for the hydraulic actuator.

5. A bedding load of $98.1 \mathrm{kN}$ was applied slowly $(5 \mathrm{kN} / \mathrm{s})$, to ensure stability for subsequent $3 \mathrm{~Hz}$ cyclic loading. The bedding load was held for a short period before being reduced to $5 \mathrm{kN}$, and counted as the first loading cycle in subsequent analyses.

6. Sinusoidal cyclic loading was then applied at $3 \mathrm{~Hz}$, between $5 \mathrm{kN}$ (minimum) and $98.1 \mathrm{kN}$ (maximum).

7. At the end of each test, everything was removed from the apparatus including the ballast, and replaced afresh for the next test to ensure repeatability of initial conditions.

Calculations using the beam on an elastic foundation (BOEF) model (Timoshenko, 1927), together with the results of previous published work and recommendations by railway authorities (e.g. Network Rail, 2005) show that in typical ballasted railway systems approximately $50 \%$ of the load is carried by a sleeper immediately below an axle. Thus, the vertical load of 10 tonnes or $98.1 \mathrm{kN}$ applied in the current tests corresponds to an approximately 20 tonne axle load. This is higher than most passenger trains (10 to 15 tonnes) but less than the maximum freight axle loads which may be up to 30 tonnes on mixed use routes, and even higher on dedicated mining routes. The choice of load is therefore somewhat arbitrary, and higher or lower values could be justified for particular circumstances. However, the influence of the load magnitude is not a variable that was investigated in the current tests, in which the intention was to apply a realistic and constant load within the typical range, and to maintain comparability of load from test to test. Investigations using the same apparatus with different loads (Abadi et al., 2016) found that settlements scaled approximately with the load. The loading rate of $3 \mathrm{~Hz}$ was adopted to allow each test to be completed in an acceptable timeframe ( 12 days for 3 million cycles). At $3 \mathrm{~Hz}$, over the amplitudes of movement present (approaching some few millimetres - see later results), accelerations are insignificant compared with 
gravity - hence these tests are essentially quasi-static. Although others have attempted to justify loading rates based on axle passing frequencies, these are not the frequencies of loading transmitted through to the sleepers and track bed (see, for example, Bian et al., 2015, Ju et al., 2009, Le Pen et al., 2016, Milne et al., 2017), which are dominated by the vehicle passing frequency and key multiples thereof.

Most routes carry a variety of passenger and freight services. Passenger trains may vary from 1 to 12 carriages in length, with freight trains potentially much longer. 3 million cycles represents approximately the interval between maintenance (tamping) on a mid-life, busy, ballasted railway; equating to approximately $100 \times 10$ vehicle trains per day for 2 years, each having a 20 tonne axle load and four axles per vehicle.

A $12 \mathrm{~mm}$ thick rubber mat placed at the bottom of the apparatus, below the ballast bed, modelled a uniform, slightly compressible subgrade. The load/deflection behaviour of the rubber mat when loaded through discrete ballast grain contacts is not directly predictable using the material properties of the rubber such as Young's modulus and Poisson's ratio. However, testing with the mat loaded through ballast grain contacts (Abadi, 2014) confirmed that the rubber mat behaved as intended. Thus the tests reported in this paper focussed on the performance of the ballast bed alone, with the rubber mat contributing to an overall cyclic movement of $\sim 0.5 \mathrm{~mm}$ in the baseline test, typical of well-performing track in the UK (Bowness et al., 2005).

\section{Instrumentation}

On mono-block sleepers, vertical LVDTs were placed at each of the four corners and in the middle of each long edge (six in total). Eight LVDTs were placed on twin-block sleepers, one on each corner of each block. A horizontal LVDT at the sleeper end showed no significant lateral movement in any of the tests. Vertical LVDT data were recorded at a frequency of $100 \mathrm{~Hz}$ and processed to determine the

- permanent settlement - a single area weighted average value representative of the whole sleeper

- resilient deflection within cycles, including the deflected shape of the sleeper

- spring stiffness - evaluated using both the area weighted average deflection and the average deflection at each sleeper end.

Further measurements to evaluate the mechanisms controlling the observed load-deflection response of the sleeper were made as follows (further details are given in Abadi, 2015):

- Pressure paper, a thin film incorporating micro-encapsulated colour forming and developing materials (Fuji Film, 2013), was used to record the number and area of contacts at the sleeper / ballast interface. Sheets of pressure paper with stated sensitivities in the range 10 to $50 \mathrm{MPa}$, of measuring area $200 \mathrm{~mm} \times 250 \mathrm{~mm}$, were placed at the sleeper soffit in each test (one below the middle and one directly under each railseat). The pressure paper was left in place for the entire test, hence gave a cumulative record of contact positions over the whole of the loading history.

- Photographs of the ballast shoulder were taken and analysed at key stages of the test, to assess ballast shoulder movement.

- The degree of ballast grain breakage at the sleeper / ballast interface after completion of cyclic loading was investigated by a visual survey and weighing individual ballast grains. The visual survey involved counting the number of broken grains, and detected only breakages that could be seen by eye. Fifty randomly-selected ballast grains retained on a $31.5 \mathrm{~mm}$ sieve were brushed, washed, oven-dried, marked, weighed and placed directly underneath the sleeper prior 
to each test. These were recovered and weighed after testing, to determine mass loss through attrition, contact point crushing and other minor damage.

- Four pressure plates, each $300 \mathrm{~mm}$ high $\times 250 \mathrm{~mm}$ wide, were placed along the inside wall on one side of the apparatus to measure horizontal stresses within the ballast in the direction along the track. Each $12 \mathrm{~mm}$ thick steel plate was supported by four, $10 \mathrm{~mm}$ thick load cells giving a total thickness similar to the wooden panels attached to the remainder of the side walls of the apparatus. The top of each plate was set level with the sleeper soffit $(300 \mathrm{~mm}$ above the base of the apparatus). The plates were placed adjacent to each other, horizontally from the centre of the sleeper. Data from each load cell were recorded using the same logger and at the same frequency as the LVDTs.

The arrangement of the key instrumentation is shown in Figure 2.

\subsection{Materials}

\section{Sleeper}

Sleepers tested were mono-block (G44) reinforced concrete (BSI, 2009a) and timber (hardwood), and twin-block (B450, French SNCF type) reinforced concrete (BSI, 2009b). The base (footprint) area of each sleeper tested was approximately rectangular. The timber sleeper was cuboid in shape. The concrete sleepers were approximately cuboid, but their cross sectional profiles were trapezoidal with the top surface sloping slightly downward at the railseats. The major dimensions of the sleepers are shown in Table 2. Full dimensional details are given from British and European standards (BSI 2009a \&b). The sleepers selected for evaluation represent typical examples; while there are a number of different concrete mono-block sleepers in use with slightly different dimensions, their mass, bending stiffness and major dimensions are not dissimilar to those tested. The twin-block sleepers tested were of the type developed by SNCF for use on high speed lines in France, and have also been used on the UK high speed route HS1.

There are clearly differences in bending stiffness and base contact areas between the various sleepers tested, and their materials of different durability. The tests in this study evaluated only the relative performance of these sleepers when they are in good condition. Further evaluation and / or studies would be required to assess each sleeper type for durability, and could lead to modifications to the designs and materials while retaining the most beneficial mass, bending stiffness and ballast contact properties identified in this paper.

\section{Ballast}

The ballast was from Cliffe Hill quarry, Leicestershire, U.K., which provides British and EU Standard compliant crushed granite aggregates for road and rail applications (BSI, 2009c). The ballast grading in all tests was to the current UK Network Rail gradation A (BSI, 2013). The ballast used has been selected to be representative of modern crushed igneous rock ballast that would be acceptable for use in most if not all locations globally, although for logistical reasons it is sourced from a UK quarry. The precise performance characteristics of the ballast are not the focus of the current study, but triaxial tests on parallel gradations of the same parent material confirmed a strength and stiffness comparable with the range of values reported in the literature for crushed igneous rock ballast materials (Aingaran, 2014, Le Pen et al., 2014 Aingaran et al., 2018). Further information on the ballast, including results from standard tests, is given in Laryea et al., (2014).

In each test, repeatability of the initial ballast state was achieved through a carefully controlled placement and compaction procedure giving a consistent initial density of $\sim 1610 \mathrm{~kg} / \mathrm{m}^{3}$. 


\section{Under Sleeper Pads (USPs)}

Two types of typical "performance" USPs (Tiflex Ltd. FC500 and FC208GF) were tested, denoted USP1 and USP2 (Table 1). USP 1 comprised a blend of thermoplastic materials and elastomeric inclusions in a single layer. USP 2 was of sandwich construction, with a core of high quality cellular rubber bonded cork covered by outer protection layers. According to the categorisation proposed by Auer et al (2013), USP 1 is stiff and USP 2 is soft and their performance may be considered comparable with similar USPs available from different manufacturers. USPs were attached to both mono-block G44 (BSI, 2009a) and twin-block concrete (B450) sleepers (BSI, 2009b) using epoxy glue.

\section{Tests carried out}

Seven tests were carried out to between 3 million and 6 million loading cycles, as summarised in Table 2.

\section{Results \& Discussion}

In the presentation and discussion of results, the following definitions are used:

- Permanent settlement: the irrecoverable vertical movement at the minimum load of $5 \mathrm{kN}$.

- Resilient deflection: the range of movement within a single cycle associated with reducing the load from its maximum to its minimum value.

- Spring stiffness: the change in vertical load per rail divided by the resilient deflection. Although there are various definitions in the literature, the definition used in this paper is consistent with the "dynamic sleeper support stiffness" determined from a falling weight deflectometer test (Sharpe and Govan, 2014). It has units of $\mathrm{kN} / \mathrm{mm}$ and may be calculated using either a single characteristic deflection representing the whole sleeper, or the deflection at a specific location on the sleeper.

\subsection{Permanent Settlement}

To obtain a single characteristic settlement for the whole sleeper, LVDT measurements were averaged using an area weighted method, in which the settlement of any point on the sleeper was taken as the settlement of the nearest LVDT. Figure 3 shows the permanent settlement against the number of loading cycles on a logarithmic scale for all seven tests. Zero on the $y$-axis corresponds to the sleeper level (a) before the slow first load cycle was applied, and (b) after 10 loading cycles.

Figure 3a shows a significant variation in the magnitude of settlement over the initial loading cycle, as indicated by the different settlements in each test at the end of the second cycle. This is due to the small number of ballast particles initially in contact with the sleeper soffit (Shenton, 1984; Abadi et al., 2015), which results in an initially variable and relatively unstable interface. The rate of accumulation of permanent settlement per cycle generally reduces with the number of cycles. Permanent settlement increases approximately linearly with the logarithm of the number of loading cycles, as is often suggested in the literature (Dahlberg, 2001). However, on the logarithmic plot there is an apparent increase in slope in some tests at about 1 million cycles. The shapes of the lines in Figure 3 are consistent with field measurements of settlement reported by Shenton (1984) for sites in different parts of the world. However, Shenton's data include settlement of the subgrade, hence are unsurprisingly 2 to 3 times greater at 1 million cycles.

To eliminate the bedding associated with the initial loading cycles and facilitate comparison, the permanent settlements were zeroed after 10 loading cycles (Figure 3b). The resulting permanent settlement at key stages in all tests is compared with the baseline (standard G44 concrete monoblock sleeper on standard Network Rail ballast) in Table 3. 
Figure 3 and Table 3 show some important trends. At 3 million loading cycles, all of the other sleepers tested performed better than the baseline. The permanent settlement of the timber sleeper was $5 \%$ less, and of the twin-block sleeper $26 \%$ less, than the baseline. The attachment of USPs 1 and 2 reduced the permanent settlement of the G44 mono-block concrete sleeper by 32-34\%, although there was relatively little benefit in using the USPs with the twin-block sleeper (settlements reduced by $29-31 \%$ relative to the baseline test, compared with $26 \%$ for the twin-block sleeper without USPs). As discussed later, the improvement in performance of the timber sleeper and the sleepers with USPs is attributable to the indentation of the ballast particles into the softer material on the soffit providing more stable contacts for load distribution.

To investigate the potential for reducing the rate of settlement after greater numbers of loading cycles, the settlement that occurred between 2 million and 3 million loading cycles (in $\mathrm{mm}$ and as a percentage difference from the baseline test) is shown in Table 3. Over the range 2-3M loading cycles, USPs represent the most effective intervention for reducing settlement (by $40 \%$ and $66 \%$ compared with the baseline case), while the timber sleeper shows some possible deterioration in performance. It might be noted that a reduction in the number of cycles needed to reach a specific permanent settlement is probably a more appropriate measure of the benefit of an intervention than the permanent settlement at a given number of cycles.

\subsection{Resilient Deflection}

For sleepers on freshly laid or just-tamped ballast, contact is often idealised as being mainly below the railseats (Raymond, 1978). This is because on laying or tamping, ballast is packed beneath the railseats to provide support immediately beneath the rails. However, this pressure distribution can then change with loading cycles. Especially when the ballast is untamped, a gap can develop below the ends of mono-block sleepers giving rise to a condition known as centre binding (Raymond, 1978; Turcke and Raymond, 1979). A significant portion of the rail load is then carried by the ballast below the centre of the sleeper. Centre binding results in the resilient deflection over a load cycle at the ends or corners of the sleeper (shown in Figure 4a) being greater than in the centre (Figure 4b). The deflected form of the sleeper is hogging (tension on the upper face) rather than sagging (tension on the lower face).

Figure 4 shows that the deflection at the sleeper ends (corners) and centre either reduces or increases with increasing number of loading cycles. Figure 5 shows the ratios of end to middle resilient deflection as a function of the number of loading cycles for each test.

In all tests, the ratio of the resilient deflection at the sleeper end to that in the middle started at or close to 1.0 (Figure 5). As loading continued,

- in the baseline and timber sleeper tests, the ratio of end to middle resilient deflection increased, indicating hogging or centre binding. However, the timber sleeper showed a much greater ratio, probably owing to the much lower bending stiffness of the timber sleeper compared with its concrete counterpart.

- in the test on the twin-block sleeper, and in all tests with USPs, the ratio of end to middle resilient deflection was more constant, indicating uniform movement.

These trends are summarized in Table 4.

In the field, centre binding of mono-block concrete sleepers may cause sleeper failure (Stewart, 1985). However, careful inspection of the sleepers in the current tests revealed no signs of distress, indicating that the hogging moments experienced remained within the sleeper capacity.

The uniformity of deflection of the twin-block sleepers, with or without USPs, was facilitated by the 
relatively small bending stiffness of the metal rod joining the two blocks below each railseat and the much reduced area of ballast support.

\subsection{Spring Stiffness}

Track or sleeper support stiffness may be defined in several ways (Hunt, 2005; TSWG, 2016). Here, it is evaluated as a linear spring stiffness (i.e., load per unit deflection) per sleeper end. Figures $6 a$ and $6 \mathrm{~b}$ show the spring stiffness per sleeper end determined using the deflections measured at (a) the sleeper corners and (b) all LVDTs, based on the area weighted method.

Figure 6a shows that for the mono-block sleeper, the spring stiffness based on the corner measurements increased up to a certain number of loading cycles before then gradually decreasing and perhaps tending to a constant value. This is consistent with the development of a hogged sleeper shape and centre binding, with increasing number of loading cycles. Conversely, tests on twin-block sleepers and G44 sleepers with USPs showed a consistent increase in spring stiffness with number of loading cycles. The attachment of USPs to both G44 and twin-block sleepers reduced the absolute value of resilient stiffness at a given number of loading cycles, but gave a more consistent pattern with the stiffness gradually increasing with number of loading cycles, perhaps tending to a steady value.

Figure $6 \mathrm{~b}$ shows a trend of increasing area weighted spring stiffness with number of loading cycles for all tests because the centre deflection of a hogging sleeper reduces, thereby reducing the average. This is more representative of the overall behaviour than the four-corner spring stiffness, in that it uses all measurement locations on the sleeper. However, it is still important to consider differential movements between the corners and the centre to assess any tendency for centre binding.

The spring stiffness was greatest in the baseline test, and reduced with the attachment of USPs and for twin-block sleepers. However, this reduction in spring stiffness can be allowed for in design (e.g. by specifying stiffer railpads between the rails and the sleepers), and could be exploited - for example, to compensate for a sudden increase in the stiffness of an underlying support as may occur when the railway passes over a hard substructure). USP were beneficial in giving a much smoother and more uniform development of spring stiffness as the number of loading cycles increased (Figure $6 b)$. This is probably a result of the increased number and stability of ballast grain to sleeper contacts associated with the attachment of the USP.

On an operational railway, the development of differential permanent settlement (characterised as the standard deviation of the actual from the ideal vertical level of the track) leads to the requirement for periodic maintenance by tamping. A link between the development of standard deviation and track stiffness has been postulated (e.g. Hunt, 2000, Sussman et al., 2001 Dahlberg, 2010). While this seems intuitively plausible (in that a softer support is likely to be indicative of potentially more variable conditions, leading to more variable dynamic loads and hence eventually settlements), the link is entirely empirical and is based on limited publicly available data. One of the few publications (Sussmann et al., 2001) to include real data (Figure 7) demonstrates that identifying a relationship is at best subjective.

Figure 8 shows the permanent settlement as a function of the area-weighted spring stiffness (at 3 million cycles) for each of the current tests. This suggests that where the loads and ballast are the same, so that differences in sleeper support stiffness are attributable to the sleeper itself, there is no particular relationship between support stiffness and permanent settlement. In contrast, Abadi et al (2018) showed that where the ballast characteristics are different, there is an inverse correlation between support stiffness and permanent settlement. Thus the current tests show that reductions in 
permanent settlement can be achieved for given ballast conditions by improving the load transfer interface between the sleeper and the ballast.

\subsection{Number and Area of Contacts at Sleeper/Ballast Interface}

The pressure paper was recovered at the end of each test and the number and total area of the contact regions determined. Figures 9-11 and Table 5 summarise data previously reported by Abadi et al. (2015) in an analysis of the area and number of ballast particle contacts at sleeper / ballast and ballast / subgrade interfaces. Figures 9-11 show the contacts recorded by pressure paper located at the sleeper soffit for mono-block sleepers made of different materials (Figure 9), mono-blocks with USPs (Figure 10), and twin-block sleepers (Figure 11).

Figure 9 shows that the individual contact areas are larger beneath the railseats. This is because grains nearer the sleeper ends are more easily displaced than those at the middle of the sleeper because of the relative lack of containment. The larger red areas therefore represent a merging of all the contact locations of individual grains that have moved around. Each of these larger areas was counted as an individual contact location. Figure 9 also confirms that the softer timber sleeper was associated with larger grain contact areas as a result of indentation. Similarly, individual grain contacts in the tests with USPs (Figures 10 \& 11) occupied greater areas in corresponding zones than in the test on the same sleeper with no USP.

The number of contact points was counted manually, by the same person in each case. The total contact area was determined by thresholding and segmenting the images at the same cut-off values using Adobe Photoshop CS2 software, as described by Abadi et al., (2015). Contact area data are summarised in Table 5.

The numbers of contacts for the whole sleeper given in Table 5 were estimated by summing the number of contacts for all pieces of contact paper present in each test, and multiplying this by the ratio of sleeper soffit area to paper area. The percentage contact area in Column 5 is the proportion of the area of the pressure paper that turned red. As the red areas were not necessarily all under pressure at the same time, this is likely to be an overestimate of the actual area of contact at any given time. A further approximation is introduced in assuming that the proportions of contact area are the same for the whole sleeper as for the pressure paper. There is a clear trend for softer materials to have larger contact areas and greater numbers of contacts. The one exception to this is that, unexpectedly, the monoblock test with soft USP showed a lower overall contact area than the stiffer USP (Figure 10). This is perhaps an artifact of some of the contacts beneath the right railseat for the stiff USP (Figure 10) having been more mobile.

The apparent contact pressures in column 6 were estimated by dividing the maximum applied load by the relevant contact area. They are up to two orders of magnitude greater than those estimated following AREMA (2003), which - based on a simple axle load $\div$ sleeper base area approach - gives 210kPa for a G44 mono-block sleeper.

\subsection{Shoulder Movements}

Abadi et al., (2016) demonstrated that settlement of the sleeper was due in part to the lateral movement of insufficiently-contained ballast, evidenced by the gradual movement over the course of a test of individual ballast grains down the shoulder slope.

Movement of ballast grains on the shoulder slope was assessed by comparing digital images of the shoulder surface prior to testing with images captured after various numbers of loading cycles. Figures 12 to 14 show ballast shoulder slope movements for tests on twin-block sleepers with no 
USP, USP 1 and USP 2 respectively. These figures were produced by subtracting the contrast of the image at the start of the test from the contrast of the image at the stage of the test under consideration. Subtraction of identical images gives a completely black result. If grains have moved, the images are not identical and subtraction results in an image with shades of grey and white, the extent of which indicates the overall degree of ballast grain movement.

Movement of ballast grains down the shoulder slope occurred during cyclic loading in every test. However, the degree of movement was reduced considerably by the attachment of USPS, demonstrating their benefits in reducing ballast lateral spread. This is probably due to a more uniform and stable pattern of contacts at the sleeper / ballast interface, as shown by the pressure paper data.

\subsection{Breakage}

Contact areas between ballast grains, and between a hard concrete sleeper and individual ballast grains, are small. Thus when the track is loaded, high stresses can be developed, particularly at the sleeper base. It is generally held that these high contact stresses cause the more fragile asperities of ballast grains to break off, resulting in more rounded grains and potentially a reduction in the effective (peak) frictional strength of the material (Marsal, 1967).

It was initially expected that breakage could be quantified using a breakage index determined by sieving (e.g. Hardin, 1985, Indraratna et al., 2005). However, sieving of the ballast before and after testing revealed that breakage in these tests was minimal and could not be captured using such an approach. A similar absence of breakage was observed by McDowell et al., (2005) during laboratory tamping of igneous ballast. The apparent lack of breakage in these tests can be explained by the high fracture resistance of a modern specification crushed igneous rock ballast compared with the limestone ballasts used in the past (Selig and Waters, 1994). Alternative methods of assessing ballast grain breakage / damage were therefore adopted, viz. (1) visual surveys at key locations and (2) weighing of marked individual ballast grains before and after testing.

Visual surveys were carried out to identify ballast grain breakage directly under the sleeper soffit. Broken grains occurred in most tests, but in all cases the number was small (maximum 11). There is no clear relationship between the number of broken grains and the cumulative permanent settlement (Figure 16), although the baseline test with the hardest ballast to sleeper contact interface showed the most breakage.

Breakage occurred mainly in larger grains at the edges of the sleeper. This is because the potential for grain breakage increases with grain size, owing to the greater probability of defects being present (Hardin, 1985); and because grains at the sleeper edge probably experienced the most onerous shear stresses.

Fifty individually identified and weighed grains (previously brushed, washed and oven-dried) placed beneath the sleeper showed no obvious signs of damage (splitting or breakage of asperities) when recovered. However, weighing revealed a small but consistent loss of mass (Figure 16). This could have been caused by abrasion / attrition at the contacts, and / or by dust / loose surficial material falling from the ballast during loading.

\subsection{Ballast longitudinal pressure}

The ballast longitudinal pressure (i.e., along the line of the track) measured at Plates 1 and 4 is shown as a function of the number of loading cycles in Figures $17 \mathrm{a}$ and $17 \mathrm{~b}$ respectively. These locations give an indication of the development of longitudinal stress near the centre of the sleeper (Plate 1, Figure 17a) and beneath the sleeper end (Plate 4, Figure 17b). The ballast confining 
conditions are different in each case. In all cases the pressure on plate 4 nearest the loading point (the railseat) cycles such that the maximum pressure occurred at or very close to the maximum load. For plate 1 beneath the sleeper middle, the maximum pressure sometimes corresponded to the maximum load but also sometimes corresponded to the minimum load as indicated in Table 6. More detailed assessment revealed that for the sleepers with the lowest bending stiffness in the middle (twin block and timber mono-block), the maximum pressures at Plate 1 (beneath the sleeper middle) correspond to the minimum load; whereas for the stiffer mono- block concrete sleepers the maximum pressures at Plate 1 correspond to the maximum load.

The initial ballast pressure varies from test to test. This is not surprising, as the number of ballast grains and the percentage contact area at each plate is small $(0.8 \%$ to $1.67 \%$, as indicated by $10-50$ MPa pressure paper). However, broadly consistent trends of variation in maximum pressure with cyclic loading are apparent in Figure 17 and Table 6.

The maximum ballast pressure per cycle at Plate 1 (in the middle of the sleeper) with some exceptions tended to increase with the number of loading cycles (Figure 17a). An increase in longitudinal pressure at the middle of the sleeper is consistent with the development of increasing relative support stiffness and / or ballast bulk density below the sleeper middle than elsewhere along the sleeper length. The attachment of USPs to both mono-block and twin-block sleepers tended to be associated with a lower longitudinal pressure at the sleeper middle, consistently throughout the test.

In contrast, the longitudinal pressures measured at Plate 4 (at the railseat) decreased during each test - rapidly at first, and then more gradually until a near-constant value was reached (Figure 17b). This is consistent with inadequate ballast containment, and with the observed decrease in fourcorner spring stiffness / increase in deflection with the number of loading cycles. Although the initial magnitudes of ballast pressure at Plate 4 in each test were different, the attachment of USPs to mono-block and twin-block sleepers was consistently successful in reducing the loss of ballast longitudinal pressure in the railseat / shoulder zone.

The combined effect of ballast densification below the sleeper middle and the loss of ballast support at the sleeper ends is symptomatic of centre binding. The provision of USPs reduced the tendency for centre binding in the mono-block sleepers.

\section{Conclusions}

The effects of sleeper material (timber or reinforced concrete), shape (mono-block or twin-block) and the attachment of under-sleeper pads (USPs) on the resilient stiffness and permanent settlement of typical railway sleepers on a $300 \mathrm{~mm}$ deep ballast bed over 3 million cycles of a 20 tonne equivalent axle load have been investigated. Detailed assessments of sleeper soffit / ballast contact pressures and areas; individual ballast grain breakage; ballast longitudinal pressure; ballast shoulder slope stability; and any tendency for the development of centre binding were made. From the results, the following conclusions can be drawn.

1. Mono-block sleepers (G44 and timber) tended to deform in hogging (tension at the upper face) with increased number of loading cycles - a condition known as centre binding. This was characterised by an increase in the deflection and a reduction in the ballast longitudinal stress at the sleeper ends, and a reduction in the deflection and an increase in the ballast longitudinal stress at the middle. The effect was greater for the timber sleeper than for the reinforced concrete sleeper. While the extent of hogging was insufficient to cause structural distress, the condition is undesirable in that it does not provide an adequately stable support to the track. Centre binding did not occur (as evidenced by the absence of both hogging and any build-up in 
ballast longitudinal stress at the centre of the track) in tests on twin-block sleepers, or in the test on the concrete mono-block sleeper with USPs attached.

2. For the hard granite ballast used in these tests, obvious ballast grain breakage was small (11 grains at most). The greatest breakage occurred for the hardest contact condition, directly onto the underside of a reinforced concrete sleeper. Minor attrition may have been responsible for mass losses of $0.009 \%$ to $0.047 \%$ from identified individual grains.

3. The attachment of USPs to the underside of a mono-block concrete sleeper was beneficial in:

- reducing significantly the ballast permanent settlement

- preventing centre binding and sleeper hogging at increased numbers of loading cycles

- improving ballast containment and stability at the edges of the sleeper near the ballast shoulders

- preventing any significant increase in ballast longitudinal stress at the centre of the track

These benefits result from the establishment of a more stable interface between the ballast and the sleeper soffit, involving more ballast grains and generally lower contact stresses.

The benefits of USPs for twin-block concrete sleepers were less clear, partly because twin-block concrete sleepers performed better in the above respects than their mono-block counterparts.

4. The attachment of USPs to both mono-block and twin-block sleeper soffits reduces the equivalent spring stiffness, but in a consistent and quantifiable way that could either compensate for a higher underlying stiffness (e.g. over hard substructures such as bridges and culverts) or be compensated for by the use of less stiff railpads between the rails and the sleepers.

\section{Acknowledgments}

The work described in this paper was funded by the U.K. Engineering and Physical Sciences Research Council (EPSRC) as part of the TRACK21 project (grant reference EP/H044949), with in-kind contributions from Network Rail, Balfour Beatty and Tiflex. All data supporting this study are openly available from the University of Southampton repository at DOI:10.5258/SOTON/D0656.

\section{References}

Abadi, T.C. (2015). Effect of sleeper and ballast interventions on railway track performance. PhD dissertation, University of Southampton, UK.

Abadi, T.C., Le Pen, L.M., Zervos, A., and Powrie, W. (2015). Measuring the area and number of ballast particle contacts at sleeper-ballast and ballast-subgrade interfaces. International Journal of Railway Technology (IJRT) 4, Issue 2, 45-72. doi: doi:10.4203/ijrt.4.2.3.

Abadi, T., Le Pen, L., Zervos, A. \& Powrie, W. (2016). A review and evaluation of ballast settlement models using results from the Southampton Railway Testing Facility (SRTF). Procedia Engineering 143, 999-1006.

Aingaran, S. 2014. Experimental investigation of static and cyclic behaviour of scaled railway ballast and the effect of stress reversal. PhD dissertation, University of Southampton, UK.

Aingaran, S., Le Pen, L., Zervos, A. \& Powrie, W. 2018. Modelling the effects of trafficking and tamping on scaled railway ballast in triaxial tests. Transportation Geotechnics, 15, 84-90.

Abadi, T., Le Pen, L., Zervos, A. \& Powrie, W. (2018). Improving the performance of railway tracks through 
ballast interventions. Proceedings of the Institution of Mechanical Engineers, Part F: Journal of Rail and Rapid Transit 232, 337-355.

AREMA (2003). Economics of Railway Engineering and Operations. Chapter 16 in Manual for railway engineering: systems management. Maryland, USA.

Auer, F., Potvin, R., Godart, P. \& Schmitt, L. 2013. Under Sleeper Pads in Track - the UIC project. European Railway Review, Volume 19, Issue 2.

Bian, X., Jiang, H., Chang, C., Hu, J. \& Chen, Y. (2015). Track and ground vibrations generated by high-speed train running on ballastless railway with excitation of vertical track irregularities. Soil Dynamics and Earthquake Engineering 76, 29-43.

Bowness, D., Lock, A.C., Powrie, W., Priest, J.A., and Richards, D.J. (2005). Monitoring the dynamic displacements of railway track. Proceedings of the Institution of Mechanical Engineers, Part F: Journal of Rail and Rapid Transit 221, No. 1, 13-22.

BSI (2000). BS 500:2000: Steel sleepers. British Standards Institution. London, United Kingdom.

BSI (2009a). BS EN 13230-2:2009 Railway applications; track - concrete sleepers and bearers: Part 2: prestressed mono-block sleepers. British Standards Institution. London, UK.

BSI (2009b). BS EN 13230-3:2009 Railway applications; -track - concrete sleepers and bearers: Part 3: twinblock reinforced sleepers. British Standards Institution. London, UK.

BSI (2009c). PD 6682-2:2009 Published document aggregates: Part 2: aggregates for bituminous mixtures and surface treatments for roads, airfields and other trafficked areas - guidance on the use of BS EN 13043. British Standards Institution. London, United Kingdom.

BSI (2011). BS EN 13674-1:2011. Railway applications; track - rail. In Part 1: Vignole railway rails 46 kg/m and above. British Standards Institution. London, United Kingdom.

BSI (2013). BS EN 13450:2013 Aggregates for railway ballast. British Standards Institution. London, UK.

Dahlberg, T. (2001). Some railroad settlement models - a critical review. Proceedings of the Institution of Mechanical Engineers, Part F: Journal of Rail and Rapid Transit 215, 289-300.

Dahlberg, T. (2010). Railway track stiffness variations - consequences and countermeasures. International Journal of Civil Engineering 8, No.1, 1-12.

Department for Transport (2013). Passenger $\mathrm{km}$ travelled from statistical data set table RAI0103 (franchised operators only). Available from https://www.gov.uk/government/statistical-data-sets/rai01-length-of-routedistance-travelled-age-of-stock\#table-rai0103 [accessed 06/08 2013].

Fuji Film (2013). Fuji Film Prescale Pressure Measurement Film. Available from http://www.fujifilm.com/products/prescale/prescalefilm/.

Hardin, B.O. (1985). Crushing of Soil Particles. Journal of Geotechnical Engineering 111, No. 10, 1177-1192. 
Hunt, G. (2005). Review of the Effect of Track Stiffness on Track Performance, Research Project T372. Rail Safety and Standards Board (RSSB). Research Project T372.

Indraratna, B., Lackenby, J. \& Christie, D. (2005). Effect of confining pressure on the degradation of ballast under cyclic loading. Geotechnique 55, 325-328.

Insa, R., Salvador, P., Inarejos, J., and Medina, L. (2013). Analysis of the performance of under-sleeper pads in high-speed line transition zones. Proceeding of The Institution of Civil Engineers 167, TR2, 63-77.

Johansson, A., Nielsen, J.C.O., Bolmsvik, R., and Karlstrom, A. (2006). Under sleeper pads - influence on dynamic train-track interaction. In $7^{\text {th }}$ International Conference on Contact Mechanics and Wear of Rail/Wheel System. Elsevier, pp. 1479-1487. Brisbane, Australia.

Ju, S.-H., Lin, H.-T. \& Huang, J.-Y. (2009). Dominant frequencies of train-induced vibrations. Journal of Sound and Vibration 319, 247-259.

Lakusic, S., Ahac, M., and Haladin, I. (2010). Experimental Investigation of Railway Track with Under Sleeper Pad. In Slovenian Congress on Road and Traffic, pp. 386-393. Portoroz., Slovenia.

Laryea, S., Safari Baghsorkhi, M., Ferellec, J. F., Mcdowell, G. R. \& Chen, C. (2014). Comparison of performance of concrete and steel sleepers using experimental and discrete element methods. Transportation Geotechnics 1, 225-240.

Le Pen, L.M., and Powrie, W. (2011). Contribution of base, crib, and shoulder ballast to the lateral sliding resistance of railway track: a geotechnical perspective. Proceedings of the Institution of Mechanical Engineers, Part F: Journal of Rail and Rapid Transit 225, 113-128. doi: 10.1177/0954409710397094.

Le Pen, L., Harkness, J., Zervos, A. \& Powrie, W. (2014). The influence of membranes on tests of coarse-grained materials at low cell pressures. In Geomechanics from Micro to Macro (Soga, K., Kumar, K., Biscontin, G. \& Kuo, M., eds.) Cambridge, UK. Taylor and Francis (CRC Press).

Le Pen, L., Milne, D., Thompson, D. \& Powrie, W. (2016). Evaluating railway track support stiffness from trackside measurements in the absence of wheel load data. Canadian Geotechnical Journal 53, 1156-1166.

Manalo, A., Aravinthan, T., Karunasena, W., and Ticoalu, A. (2010). A Review of alternative materials for replacing existing timber sleepers. Composite Structures 92, 603-611.

Marsal, R.J. (1967). Large scale testing of rockfill materials. ASCE Journal of the Soil Mechanics and Foundation Division 93, SM 2, 27-43.

Mcdowell, G. R., Lim, W. L., Collop, A. C., Armitage, R. \& Thom, N. H. (2005). Laboratory simulation of train loading and tamping on ballast. Proceedings of the Institution of Civil Engineers: Transport 158, 89.

Milne, D. R. M., Le Pen, L. M., Thompson, D. J. \& Powrie, W. (2017). Properties of train load frequencies and their applications. Journal of Sound and Vibration 397, 123-140.

Morgan, B. (1971). Industrial Archaeology Civil Engineering: Railways. London, Longman Group Ltd. 
Network Rail. (2005). Network Rail NR/SP/TRK/9039: Business process document formation treatments. London, United Kingdom, Network Rail.

Powrie, W. (2014). On Track : The Future for Rail Infrastructure Systems. Proceeding of The Institution of Civil Engineers Civil Engineering 167, Issue CE4, 19-27.

TSWG (2016). A Guide to Track Stiffness (edited by Powrie, W., and Le Pen, L. on behalf of the cross industry track stiffness working group (TSWG). University of Southampton, Southampton, UK, ISBN: 9780854329946.

Raymond, G.P. (1978). Design for railroad ballast and subgrade support. ASCE Journal of the Geotechnical Engineering Division 104, No. 1, 45-60.

Raymond, G. P. (1987). Subgrade and ballast requirements for 125-ton cars. Transportation Research Record 1131, 64-73.

Safari Baghsorkhi, M., Laryea, S., Mcdowell, G. \& Thom, N. (2015). An investigation of railway sleeper sections and under sleeper pads using a box test apparatus. Proceedings of the Institution of Mechanical Engineers, Part F: Journal of Rail and Rapid Transit 230, 1722-1734.

Schneider, P., Bolmsvik, R., and Nielsen, J.C.O. (2011). In situ performance of a ballasted railway track with under sleeper pads. Proceedings of the Institution of Mechanical Engineers, Part F: Journal of Rail and Rapid Transit 225, 299-309.

Sharpe, P. \& Govan, C. R. (2014). The use of falling weight deflectometer to assess the suitability of routes for upgrading. In Proceedings of the Second International Conference on Railway Technology: Research, Development and Maintenance (Pombo, J., ed.). Paper 134, doi:10.4203/ccp.104.134, Ajaccio, Corsica. CivilComp Press, Stirlingshire, UK.

Shenton, M.J. (1984). Ballast deformation and track deterioration. In Track technology, pp. 253-265 London. Thomas Telford Ltd.

Stewart, H.E. (1985). Measurement and prediction of vertical track modulus. Transportation Research Record $1022,65-71$.

Sussmann, T.R., Ebersohn, W., and Selig, E.T. (2001). Fundamental nonlinear track load-deflection behavior for condition evaluation. Transportation Research Record No. 1742, 61-67.

Taylor, H.P.J. (1993). The railway sleeper: 50 years of pretensioned, prestressed concrete. The Structural Engineer 71, No. 16.

Tiflex (2013). TRACKELAST Specialist rail solutions the high performance solution provider. Available from http://www.tiflex.co.uk/downloads/TFX-B-TRACKELAST-10092012_A4.pdf [accessed 23/05/2013 2013].

Timoshenko, S. (1927). Methods of analysis of statical and dynamical stresses in rails. In Proceedings of the Second International Congress of Applied Mechanics: pp. 407-418. Zurich, Switzerland.

Turcke, D.J., and Raymond, G.P. (1979). Three-dimensional analysis of rail track structure. Transportation 
Research Record 733, 1-6.

UIC. (2008). UIC Leaflet 713-1R: Recommendations for the use of Under Sleeper Pads-USP.

UIC 2009. Under Sleeper Pads - Semelles sous traverses - Schwellenbesohlungen, Summarising Report 4th ed. UNION INTERNATIONALE DES CHEMINS DE FER (HQ), 16 rue Jean Rey, 75015 Paris, FRANCE

Witt, S. (2008). The influence of under sleeper pads on railway track dynamics. Department of Management and Engineering. Linkoping University Institute of Technology, Sweden. 
Table 1. Properties of USPs tested (Tiflex, 2013)

\begin{tabular}{|l|l|l|}
\hline Property & USP1 & USP2 \\
\hline \hline Technical ID & FC500 & FC208GF \\
\hline Thickness & $4 \mathrm{~mm}$ & $9 \mathrm{~mm}$ \\
\hline Specific weight & $6 \mathrm{~kg} / \mathrm{m}^{2}$ & $5.6 \mathrm{~kg} / \mathrm{m}^{2}$ \\
\hline Stiffness (C Stat $_{\text {) }}$ & $0.228-0.311 \mathrm{~N} / \mathrm{mm}^{3}$ & $0.079-0.105 \mathrm{~N} / \mathrm{mm}^{3}$ \\
\hline Core (inner) material & Trackelast FC500 & Bonded cork \\
\hline
\end{tabular}

Table 2. Summary of tests carried out

\begin{tabular}{|c|c|c|c|c|c|c|}
\hline \multirow[b]{2}{*}{$\begin{array}{l}\text { Test label (for } \\
\text { graphs) }\end{array}$} & \multirow[b]{2}{*}{$\begin{array}{l}\text { Sleeper } \\
\text { type }\end{array}$} & \multicolumn{4}{|c|}{ Sleeper major dimensions (mm) } & \multirow{2}{*}{$\begin{array}{l}\text { Total load } \\
\text { cycles } \\
\text { applied } \\
\text { (millions) }\end{array}$} \\
\hline & & Length & Width & $\begin{array}{l}\text { Heights (sleeper } \\
\text { ends unless } \\
\text { otherwise stated. }\end{array}$ & $\begin{array}{l}\text { Mass, } \\
\mathrm{kg}\end{array}$ & \\
\hline Baseline & $\begin{array}{l}\text { Mono- } \\
\text { block }\end{array}$ & 2500 & 285 & 210 & 310 & 3.0 \\
\hline Twin-block & Twin-block & $\begin{array}{l}2415 \text { (840 per } \\
\text { block, } 735 \text { tie bar) }\end{array}$ & 290 & $\begin{array}{l}260 \text { (end) to } 220 \\
\text { (inside) }\end{array}$ & 230 & 4.5 \\
\hline Timber & Hardwood & 2600 & 250 & 130 & 75 & 3.5 \\
\hline $\begin{array}{l}\text { Mono-block + USP } \\
1\end{array}$ & \multirow{2}{*}{$\begin{array}{l}\text { Mono- } \\
\text { block G44 }\end{array}$} & 2500 & 285 & 210 & 310 & 3.0 \\
\hline $\begin{array}{l}\text { Mono-block + USP } \\
2\end{array}$ & & 2500 & 285 & 210 & 310 & 4.0 \\
\hline Twin-block + USP 1 & \multirow{2}{*}{ Twin-block } & $\begin{array}{l}2415 \text { ( } 840 \text { per } \\
\text { block, } 735 \text { tie bar) }\end{array}$ & 290 & $\begin{array}{l}260 \text { (end) to } 220 \\
\text { (inside) }\end{array}$ & 230 & 4.5 \\
\hline Twin-block + USP 2 & & $\begin{array}{l}2415 \text { (840 per } \\
\text { block, } 735 \text { tie bar) }\end{array}$ & 290 & $\begin{array}{l}260 \text { (end) to } 220 \\
\text { (inside) }\end{array}$ & 230 & 6.0 \\
\hline
\end{tabular}

Table 3. Permanent settlement $(\mathrm{mm})$ and reduction in settlement (\%) compared with the baseline case at key numbers of loading cycles and over selected increments of loading cycles

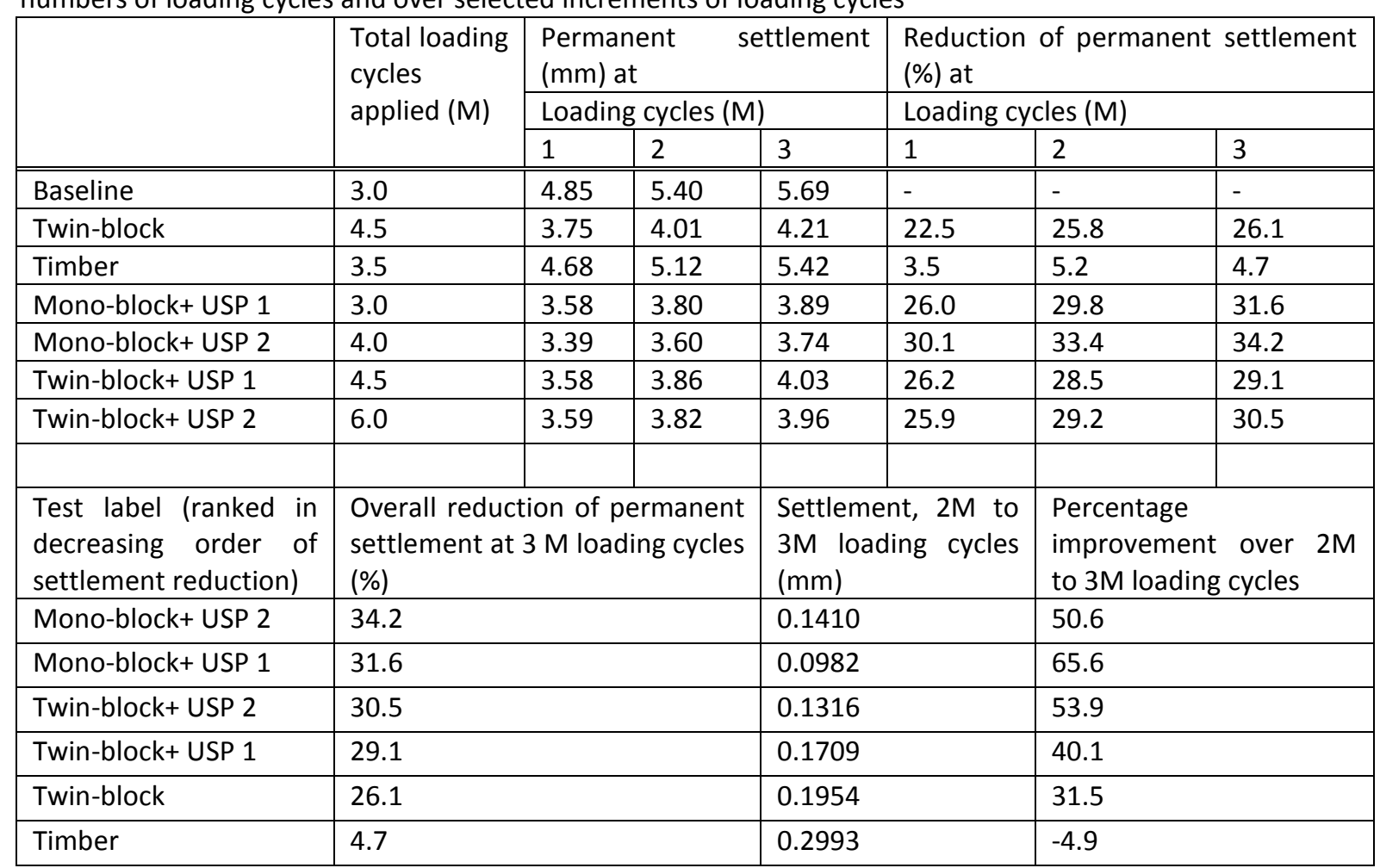


Table 4: Summary of sleeper deflection behaviour and implied deflected shape

\begin{tabular}{|c|c|c|c|c|}
\hline \multirow[t]{2}{*}{ Test } & \multirow[t]{2}{*}{$\begin{array}{l}\text { Total loading } \\
\text { cycles applied } \\
\text { (millions) }\end{array}$} & \multicolumn{2}{|c|}{$\begin{array}{l}\text { Trend with increasing } \\
\text { number of loading cycles: } \\
\text { deflection at }\end{array}$} & \multirow[t]{2}{*}{$\begin{array}{l}\text { Deflected sleeper shape } \\
\text { tends to: }\end{array}$} \\
\hline & & Ends & Middle & \\
\hline Baseline & 3.0 & Increasing & \multirow{7}{*}{ Reducing } & $\begin{array}{l}\text { Hogging (tension on } \\
\text { upper face) }\end{array}$ \\
\hline Twin-block & 4.5 & Reducing & & Uniform \\
\hline Timber & 3.5 & Increasing & & Hogging \\
\hline Mono-block+ USP 1 & 3.0 & \multirow{4}{*}{ Reducing } & & \multirow{4}{*}{ Uniform } \\
\hline Mono-block+ USP 2 & 4.0 & & & \\
\hline Twin-block+ USP 1 & 4.5 & & & \\
\hline Twin-block+ USP 2 & 6.0 & & & \\
\hline
\end{tabular}

Table 5: The number and area of particle contacts at the ballast/sleeper interface in each test, and the implied average contact pressures (extract from Abadi et al., 2015)

\begin{tabular}{|l|l|l|l|l|l|}
\hline Sleeper type & Test ID & Notes & $\begin{array}{l}\text { Number of contacts per } \\
\text { sleeper, 10-50 MPa } \\
\text { pressure paper }\end{array}$ & $\begin{array}{l}\text { Percentage } \\
\text { contactarea per } \\
\text { sleeper, 10-50 } \\
\text { MPa pressure } \\
\text { paper }\end{array}$ & $\begin{array}{l}\text { Average contact } \\
\text { pressure, MPa } \\
\text { calculated as } \\
F_{\text {max }} / A_{\text {contact }}\end{array}$ \\
\hline \multirow{3}{*}{ Mono-block } & Baseline & \multirow{2}{*}{ NR } & 147 & 0.18 & 76.5 \\
\cline { 2 - 7 } & Timber & & 420 & 1.56 & 9.7 \\
\cline { 2 - 7 } & + USP 1 & Stiff & 314 & 1.64 & 8.4 \\
\cline { 2 - 7 } & + USP 2 & Soft & 447 & 1.05 & 13.1 \\
\hline Twin-block & Baseline & NR & 243 & 0.53 & 32.3 \\
\hline & + USP 1 & Stiff & 268 & 2.91 & 5.9 \\
\hline & + USP 2 & Soft & 329 & 4.75 & 3.6 \\
\hline
\end{tabular}

Table 6: Comparison of maximum and minimum pressures with load for different sleeper interventions

\begin{tabular}{|c|c|c|c|}
\hline \multirow{2}{*}{ Sleeper type } & Test ID & $\begin{array}{c}\text { Plate 1 (centre } \\
\text { of sleeper) at } \\
\text { maximum load }\end{array}$ & $\begin{array}{c}\text { Plate } 4 \\
\text { (railseat/sleeper } \\
\text { end) at maximum } \\
\text { load }\end{array}$ \\
\hline \hline \multirow{3}{*}{ Mono-block } & Baseline & Max & Max \\
\cline { 2 - 4 } & Timber & Min & Max \\
\cline { 2 - 4 } & + USP 1 & Max & Max \\
\hline Twin-block & + USP 2 & Max & Max \\
\hline \multirow{2}{*}{} & Baseline & Min & Max \\
\hline & + USP 1 & Min & Max \\
\cline { 2 - 4 } & + USP 2 & Min & \\
\hline
\end{tabular}




\section{Figures}

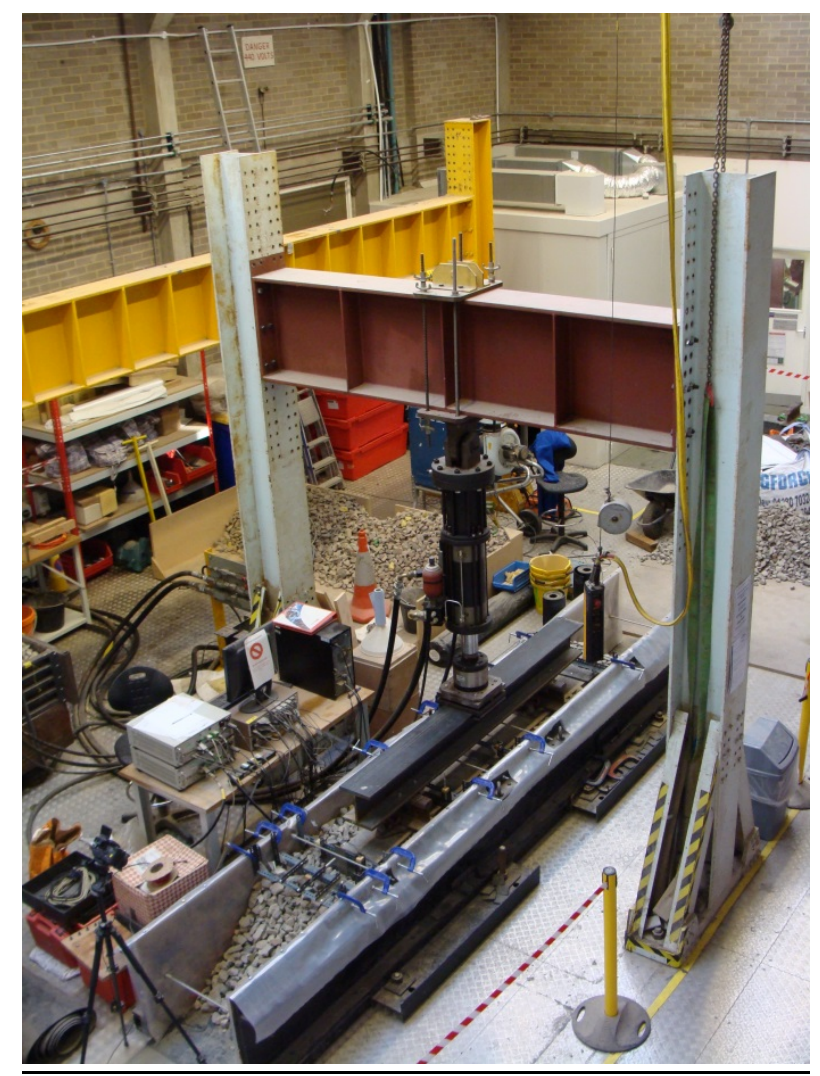

Figure 1: Test apparatus.
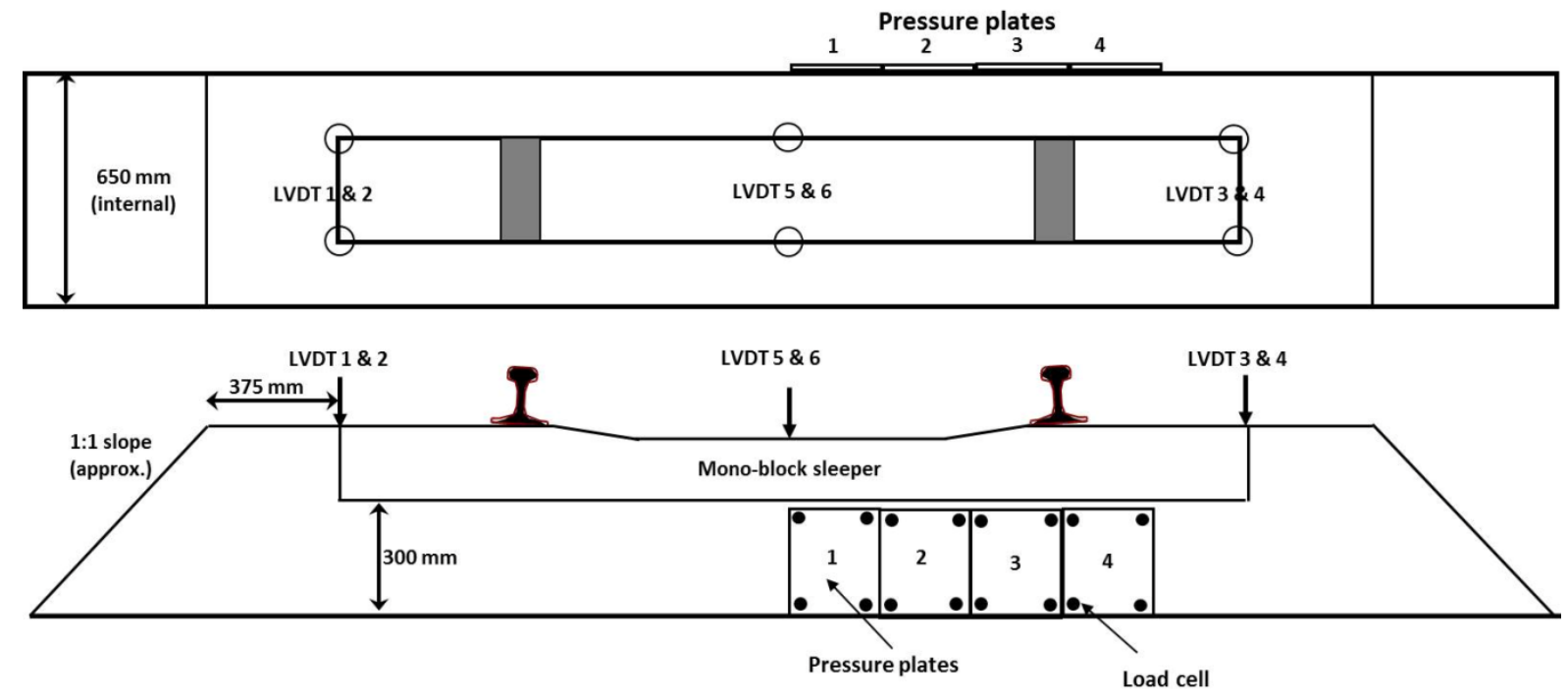

Figure 2: Test apparatus, plan view and elevation - instrumentation shown for mono block sleeper (see text for adaptations for twin block). 

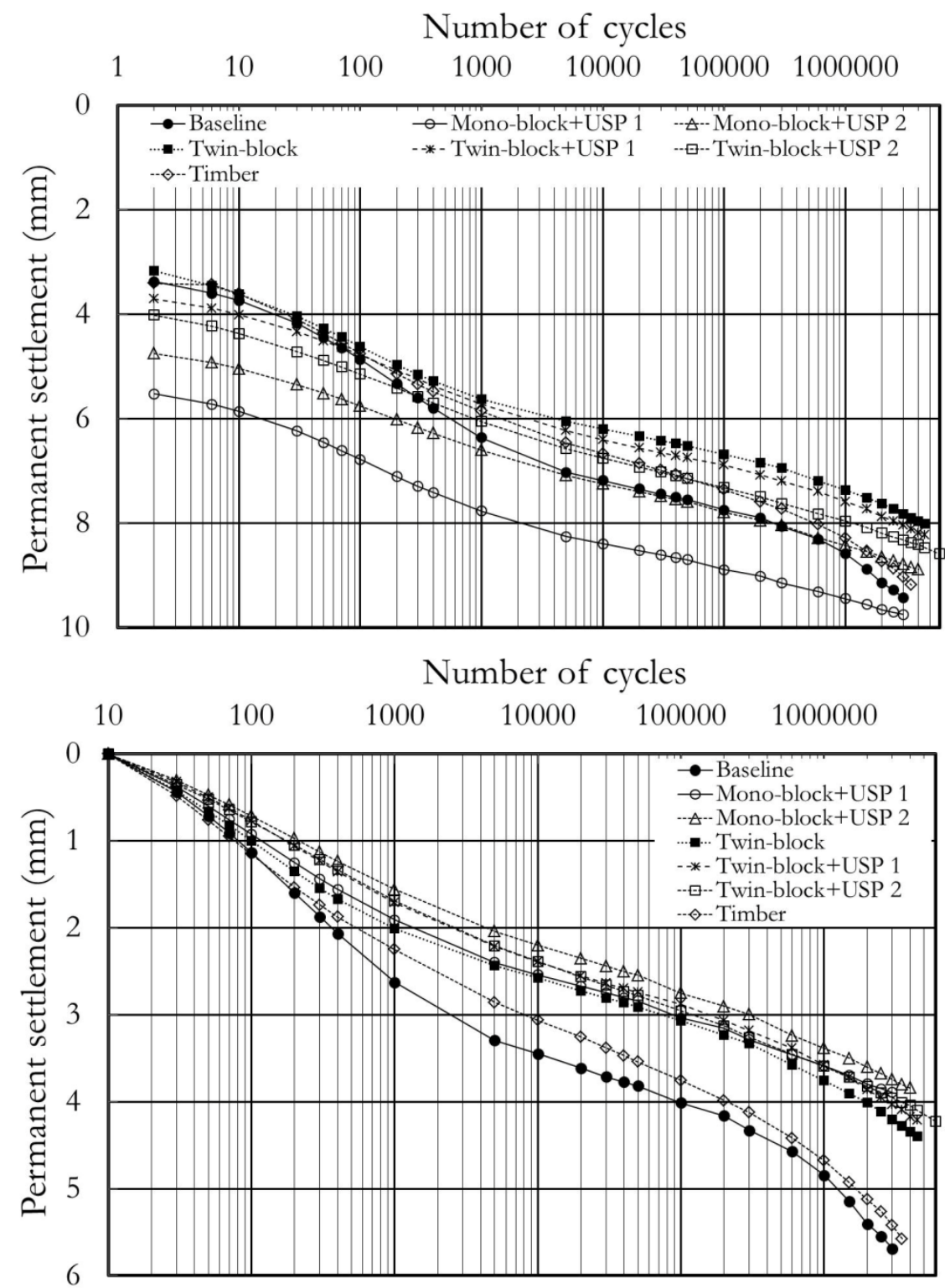

Figure 3: Permanent settlement against number of loading cycles, zeroed (a) before the first cycle, and (b) after 10 cycles. 

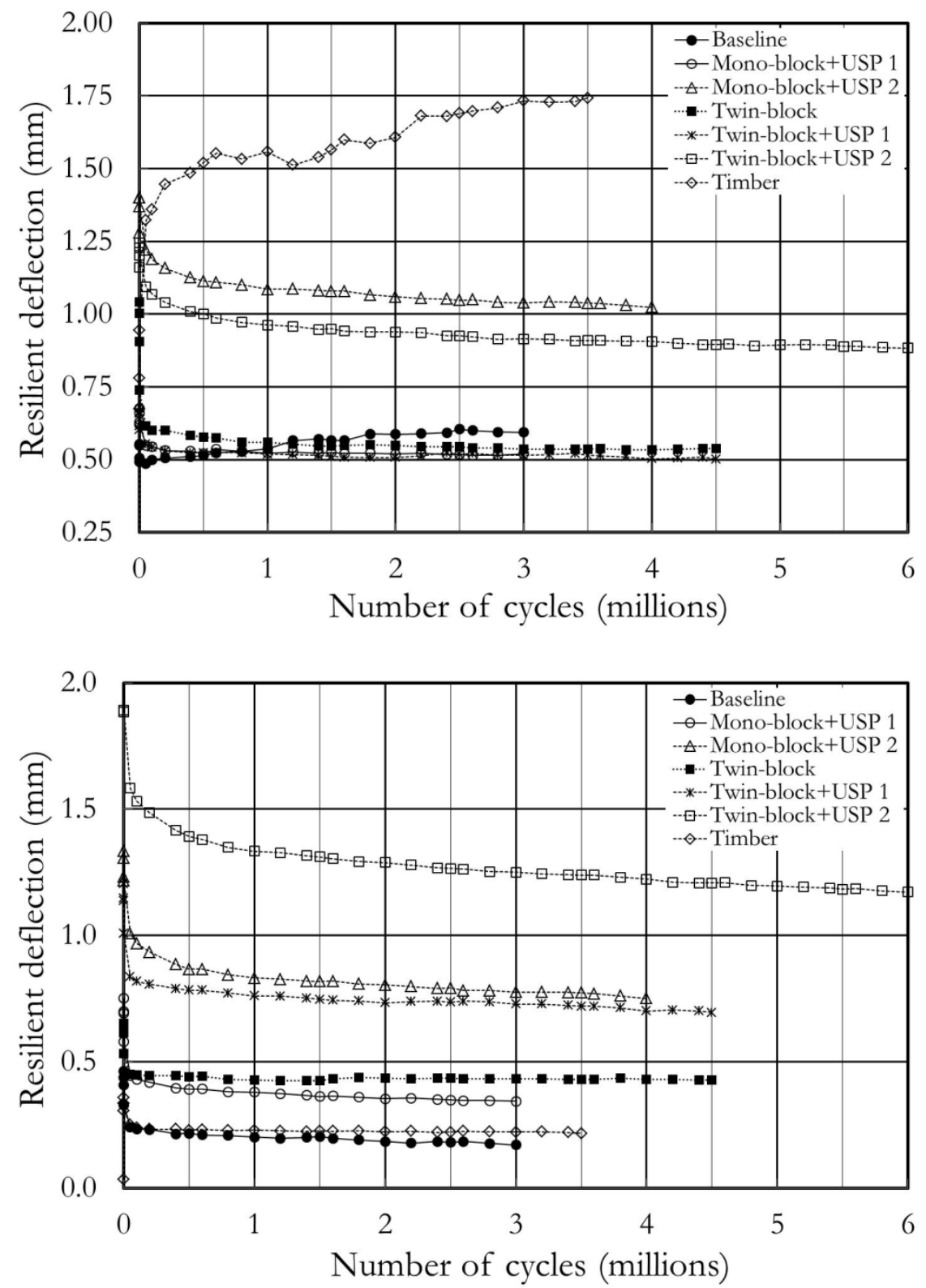

Figure 4: Average resilient sleeper deflections measured at (a) the four corners (b) the centre of the sleeper. 


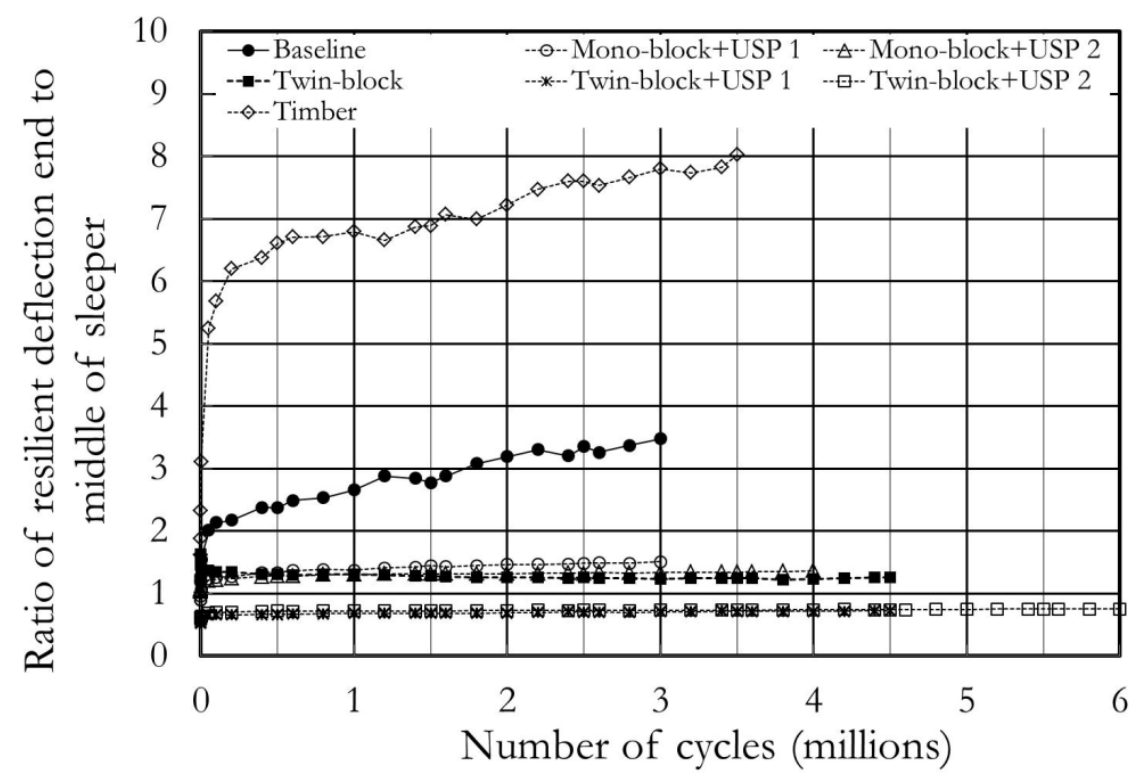

Figure 5: Ratio of resilient deflection at the end of the sleeper to that in the middle.

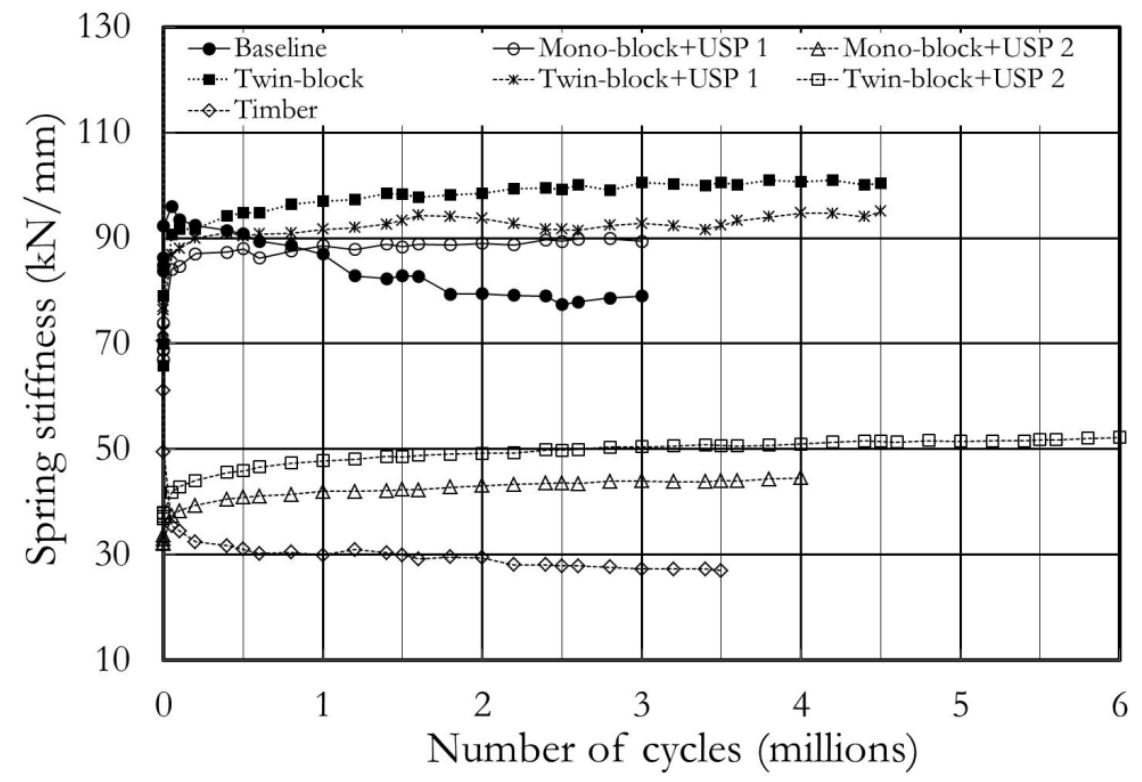




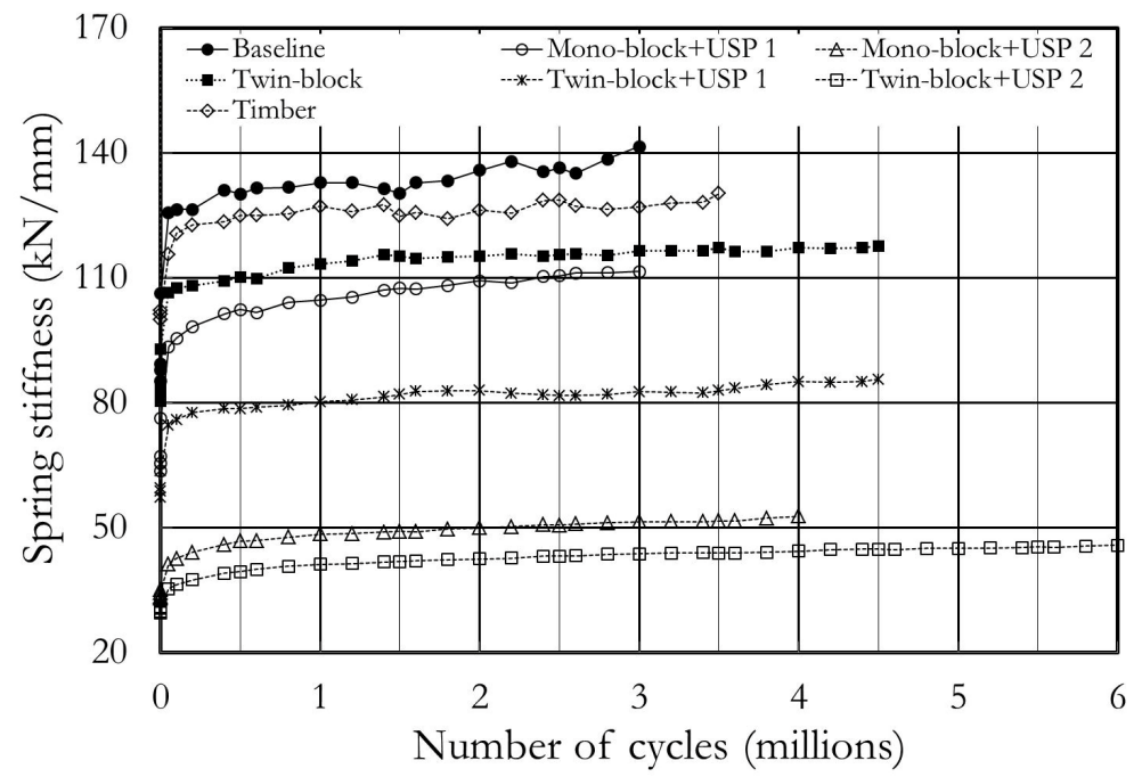

Figure 6: Sleeper end spring stiffnesses based on average deflections measured (a) at the four corners (b) over the whole sleeper (area weighted method).

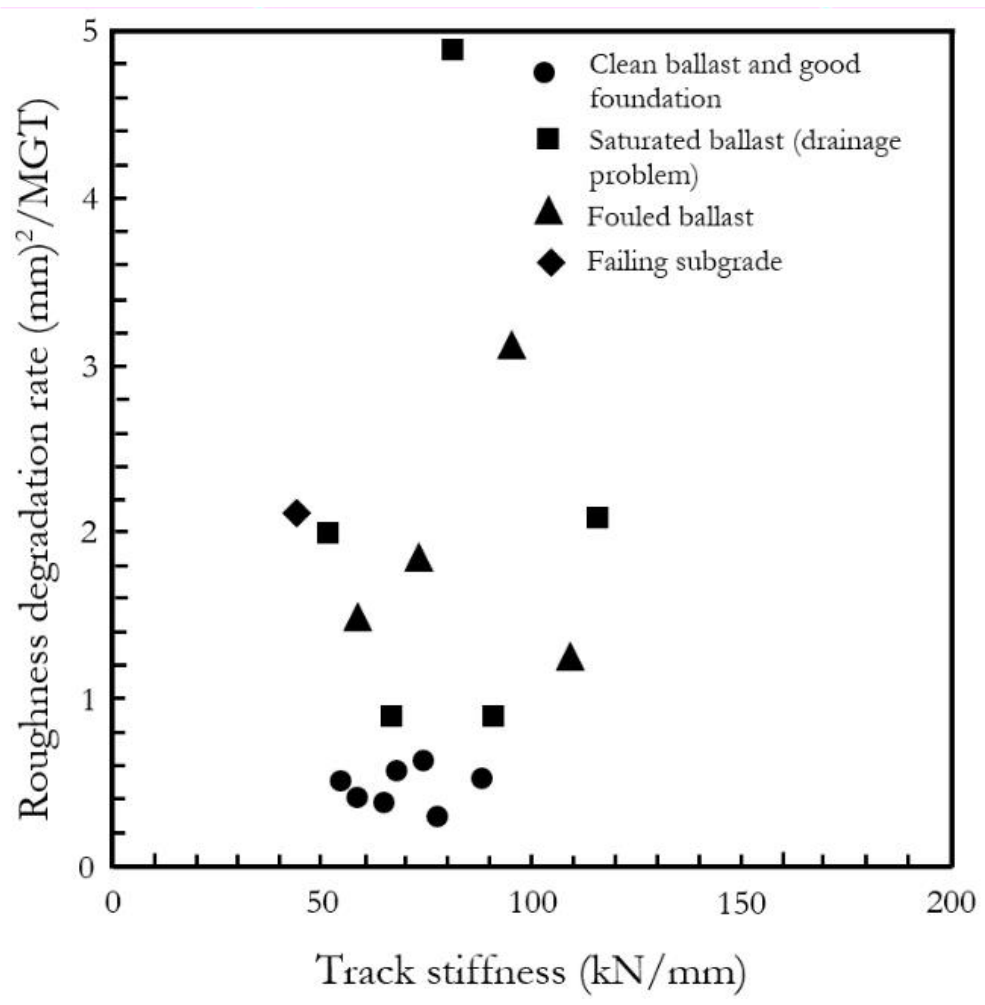

Figure 7: Relationship between track geometry degradation rate and track stiffness (after Sussmann et al., 2001). 


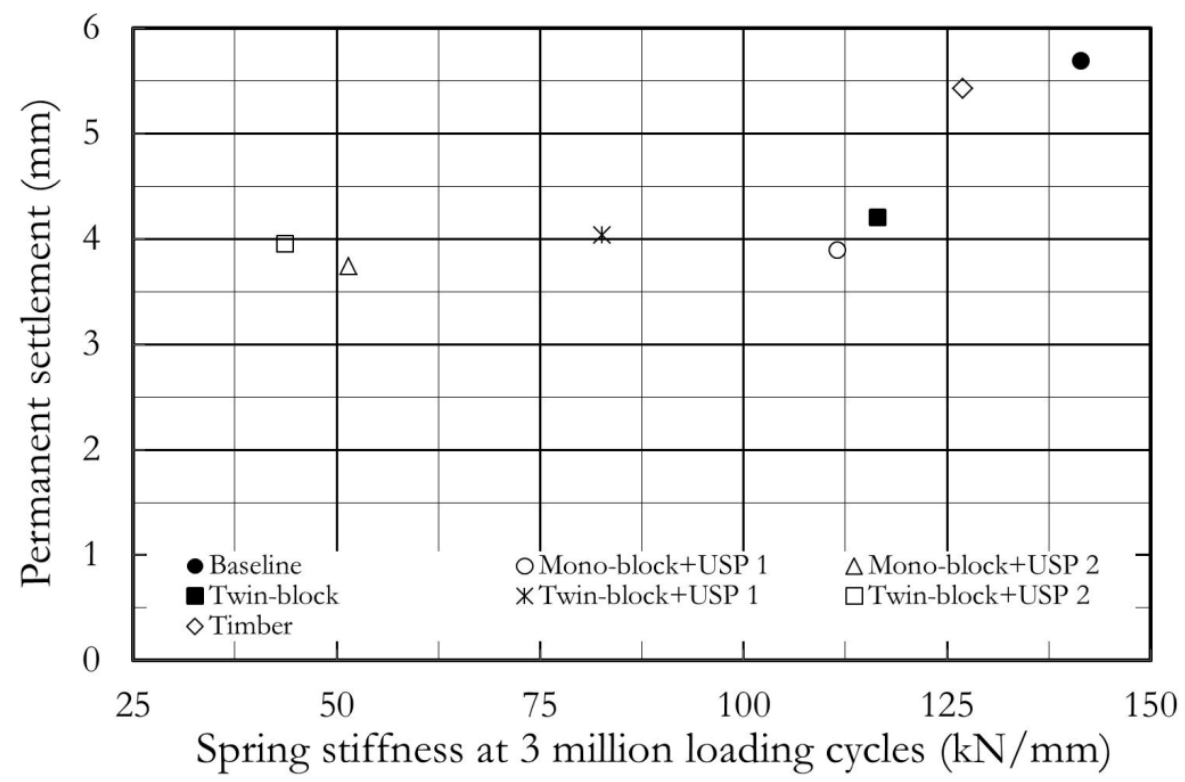

Figure 8: Ballast permanent settlement (re-zeroed after 10 loading cycles) vs area-weighted spring stiffness at 3 million loading cycles, measured in laboratory tests.

\section{Paper below:}

\section{Railseat}
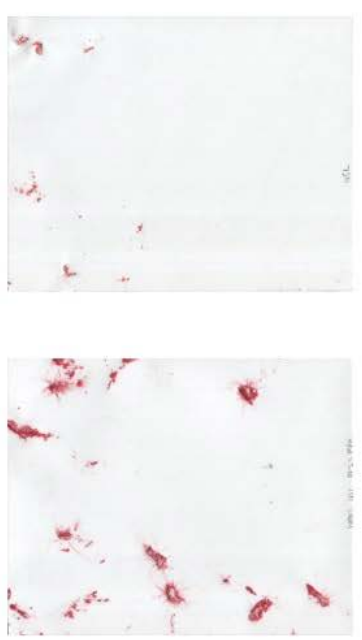

Middle
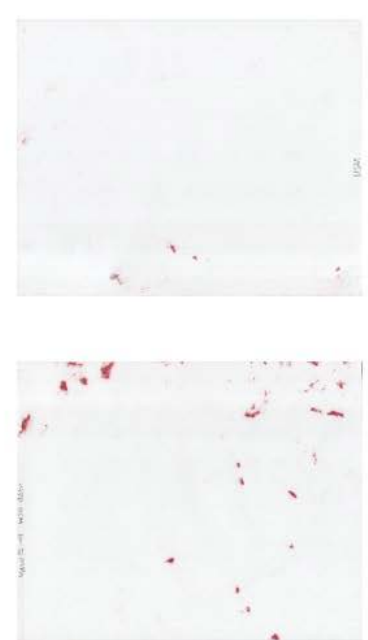

Railseat

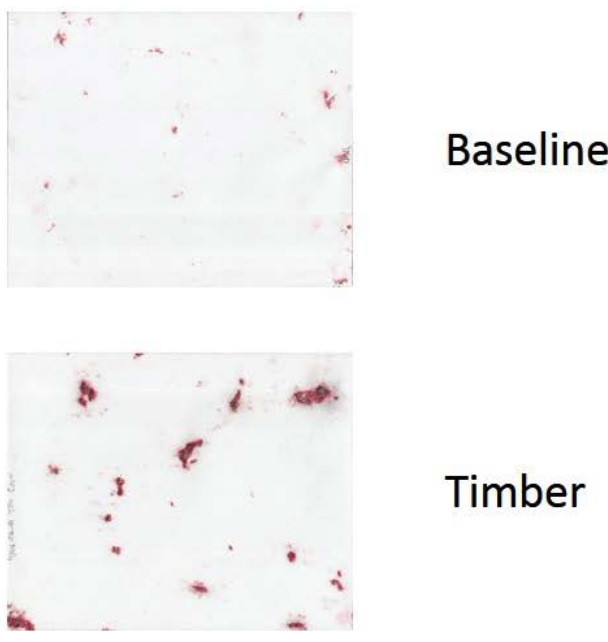

Figure 9: Grain contact histories at the sleeper/ ballast interface: mono-block sleepers (extract from Abadi et al., 2015). Red indicates locations of ballast grain/sleeper contacts $>10 \mathrm{MPa}$. 


\section{Paper below:}

\section{Railseat}
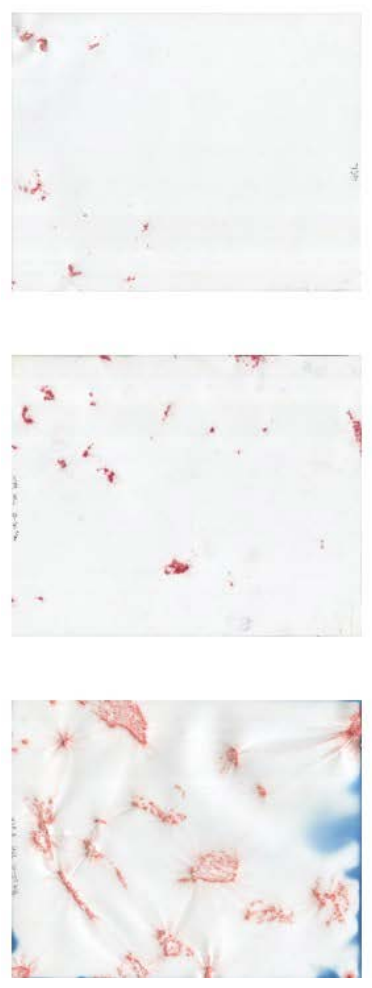

Middle
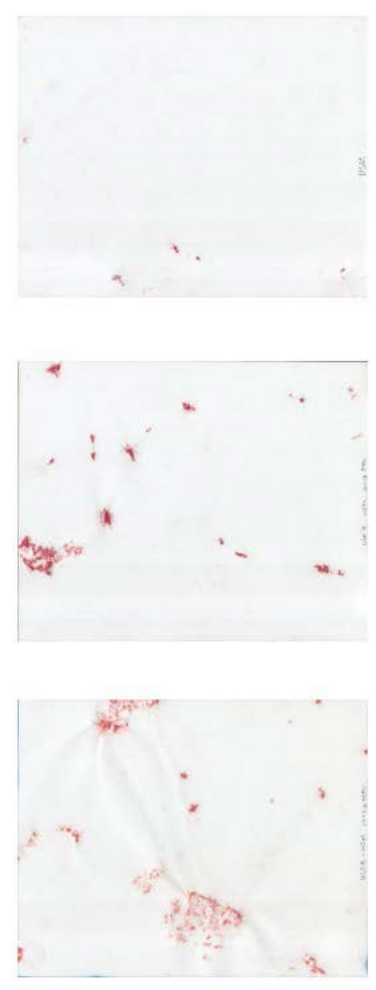

Railseat

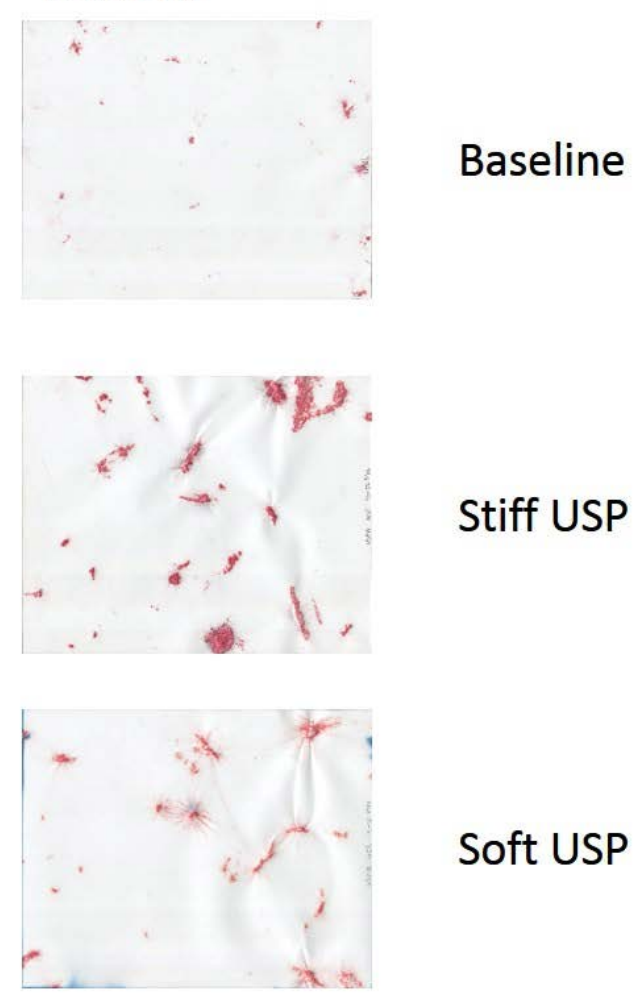

Figure 10: Grain contact histories at the sleeper/ballast interface: mono-block concrete sleeper, with and without under sleeper pads (The blue coloration on the bottom left paper is an artifact of damp ingress and is irrelevant). (Extract from Abadi et al., 2015). Red indicates locations of ballast grain/sleeper contacts $>10 \mathrm{MPa}$. 


\section{Paper below:}

\section{Railseat}
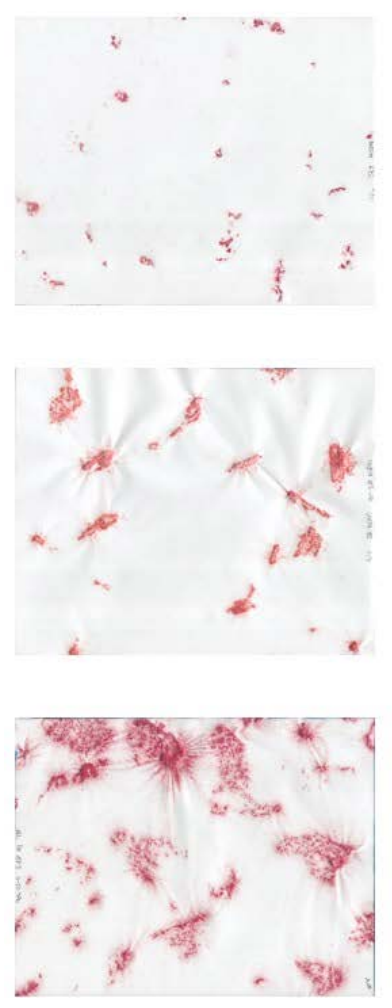

Middle

\section{Railseat}
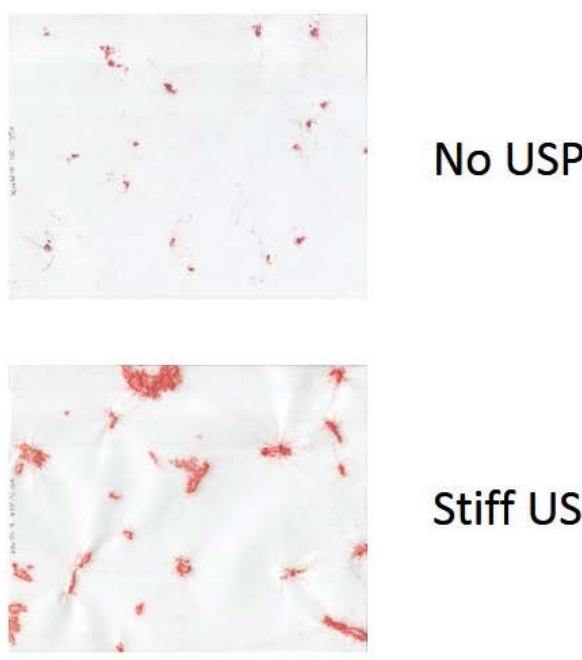

Stiff USP

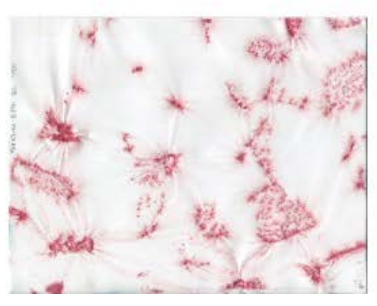

Soft USP

Figure 11: Grain contact histories at the sleeper/ballast interface: twin-block concrete sleeper, with and without under sleeper pads. Red indicates locations of ballast grain/sleeper contacts $>10 \mathrm{MPa}$. 
a)

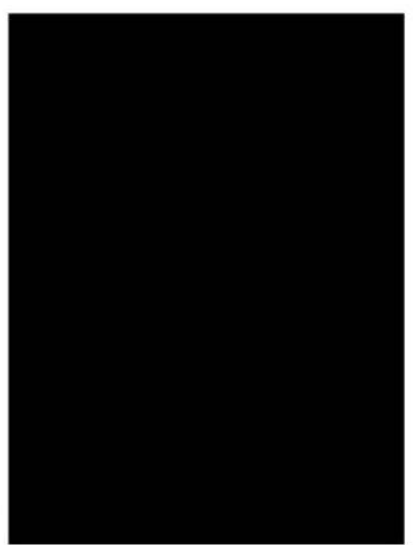

b)

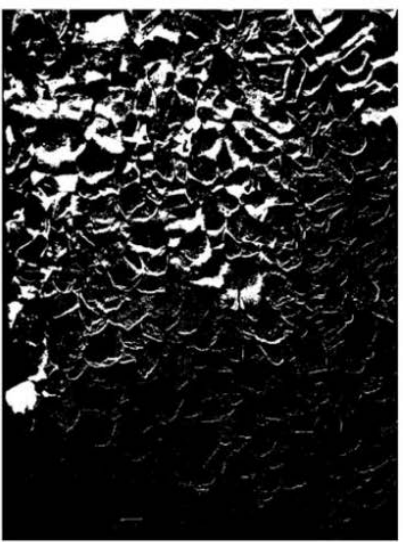

C)

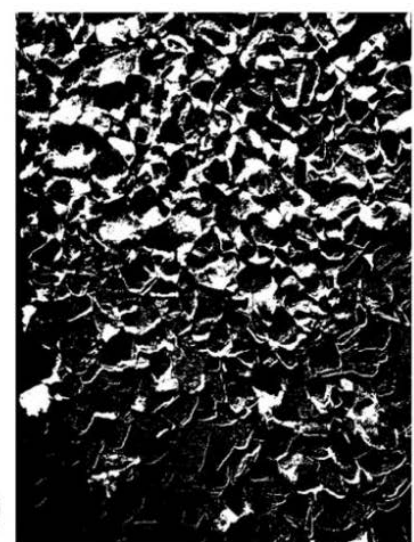

Figure 12: Ballast grain movements on the shoulder slope: twin-block sleeper test with no USP, (a) prior to testing, (b) after 0.25 million loading cycles, and (c) at the end of the test.

a)

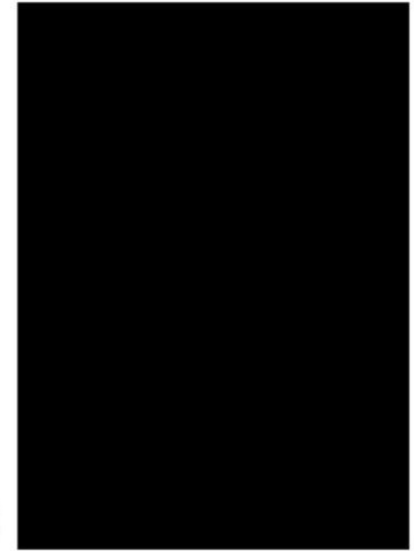

b)

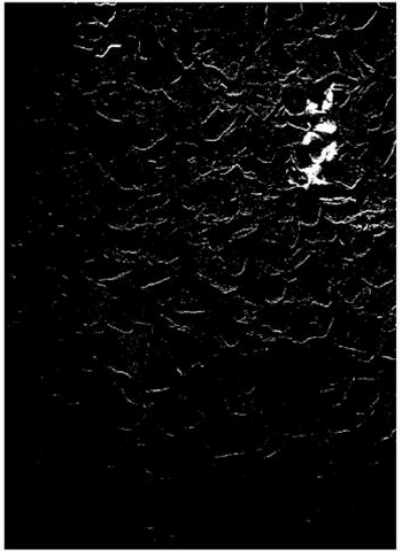

c)

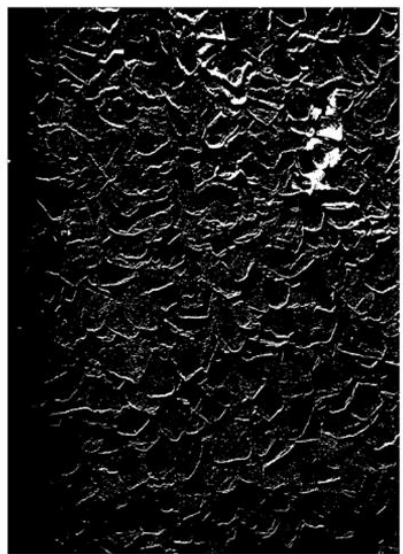

Figure 13: Ballast grain movements on the shoulder slope: twin-block sleeper test with USP 1, (a) prior to testing, (b) after 0.25 million loading cycles, and (c) at the end of the test.
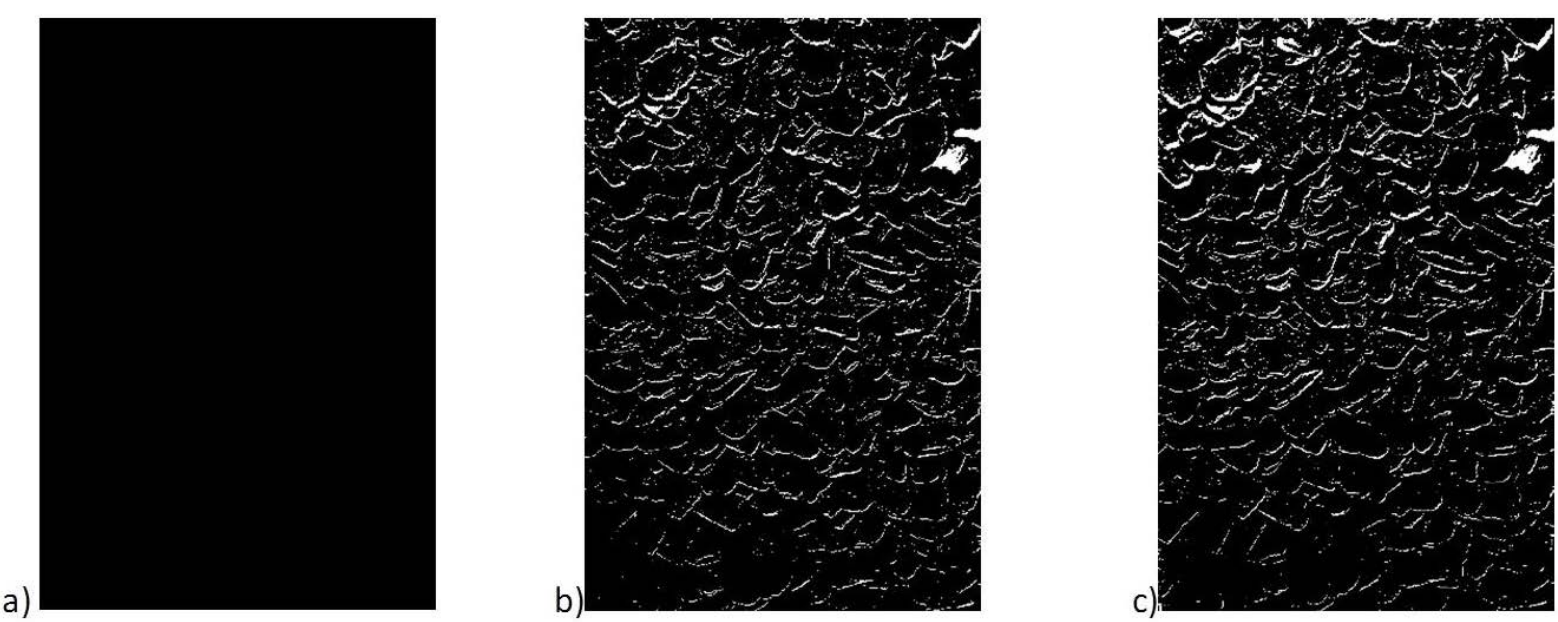

Figure 14: Ballast grain movements on the shoulder slope: twin-block sleeper test with USP 2, (a) prior to testing, (b) after 0.25 million loading cycles, and (c) at the end of the test. 


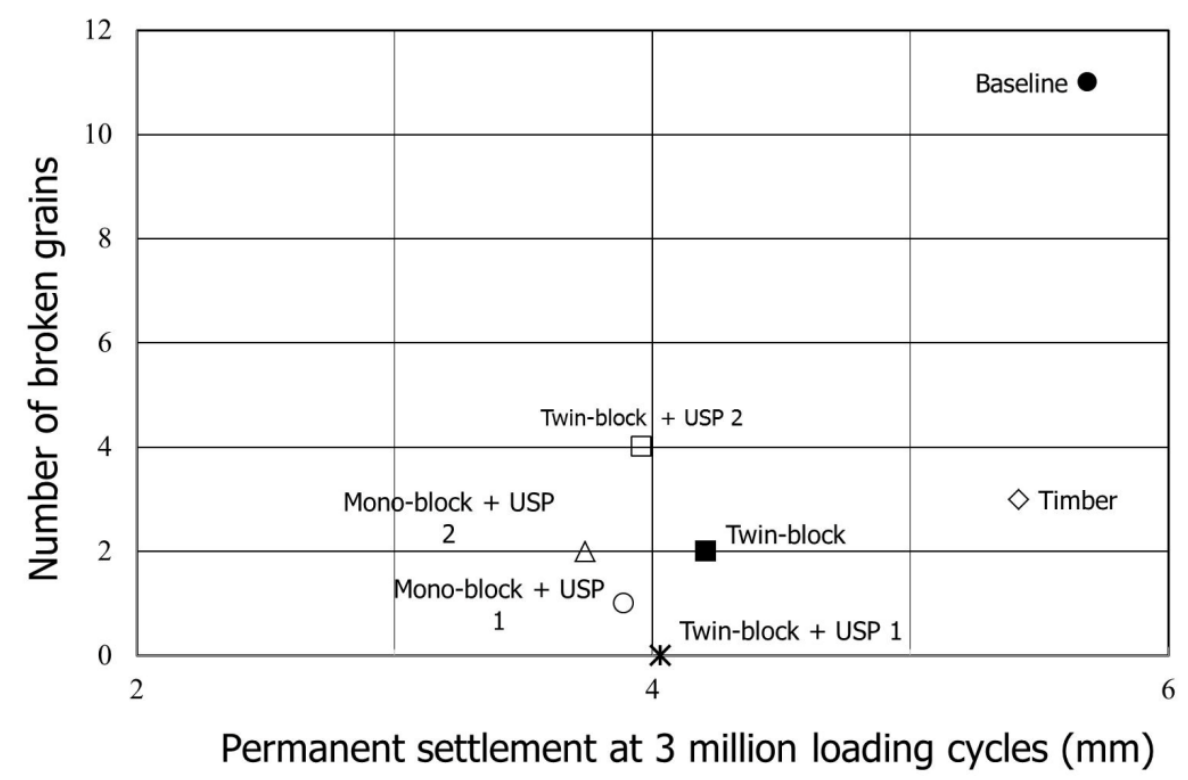

Figure 15: Number of broken ballast grains vs permanent settlement after 3M loading cycles.

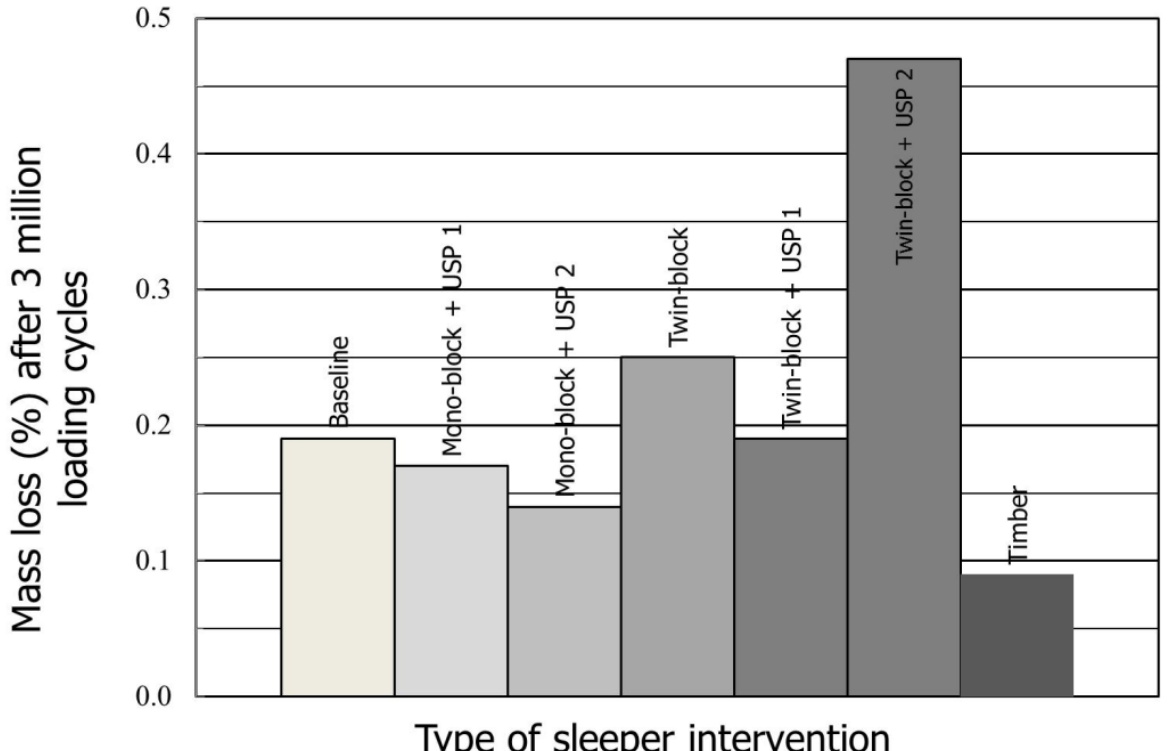

Figure 16: Percentage mass loss from selected ballast grains. 

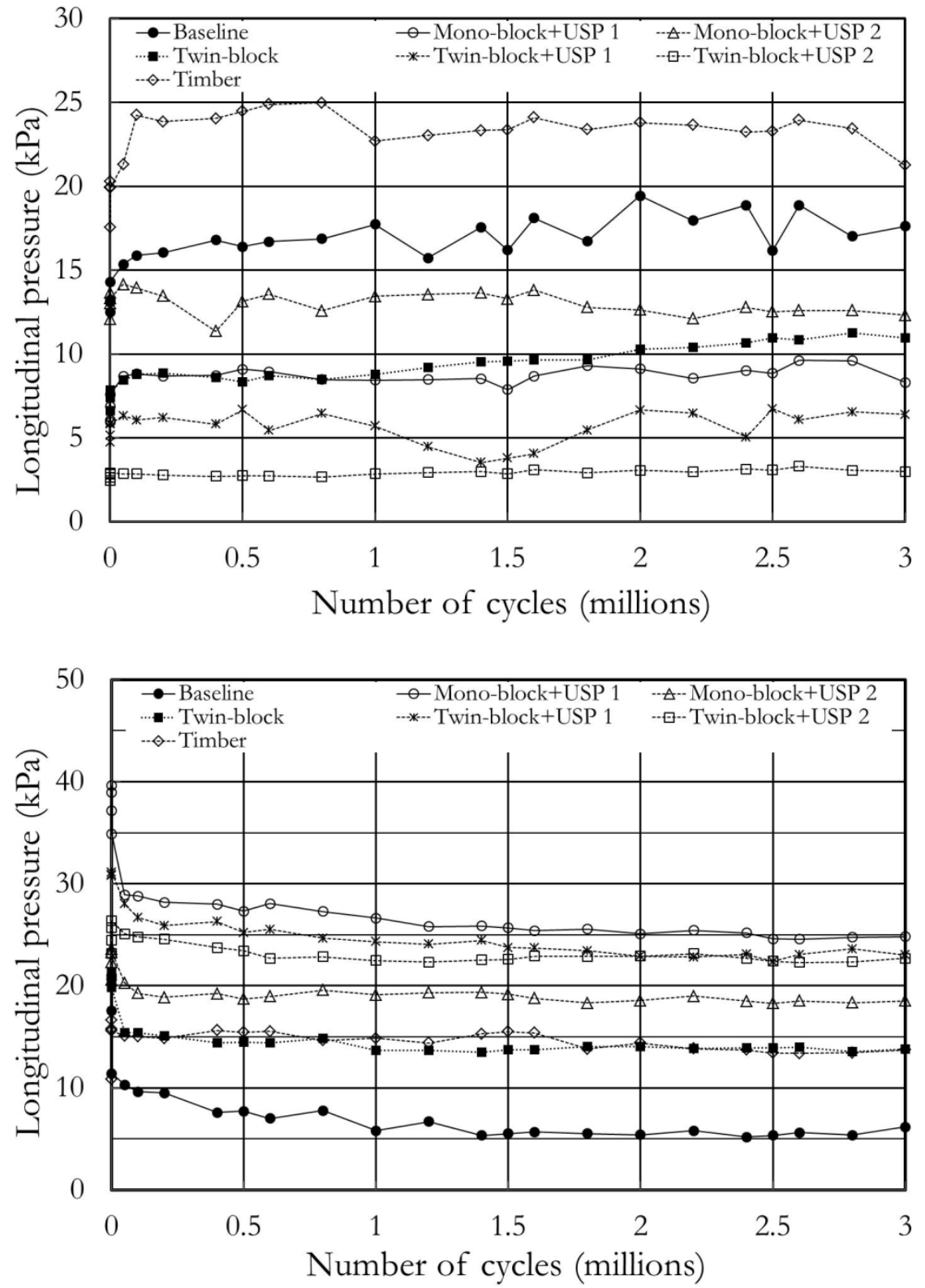

Figure 17: Change in maximum longitudinal ballast pressure with number of loading cycles, measured at (a) Plate 1 (middle) and (b) Plate 4 (railseat). 